\title{
Tin Oxides as a Negative Electrode Material for Potassium-Ion Batteries
}

\author{
Masahiro Shimizu, ${ }^{*,+, \ddagger}$ Ryosuke Yatsuzuka,${ }^{\dagger}$ Taro Koya ${ }^{\dagger}$ \\ Tomohiko Yamakami, ${ }^{\S}$ and Susumu Arai ${ }^{*,+, \neq}$ \\ ${ }^{\dagger}$ Department of Materials Chemistry, Faculty of Engineering, \\ Shinshu University, 4-17-1 Wakasato, Nagano, 380-8553, Japan \\ ${ }^{\ddagger}$ Institute of Carbon Science and Technology, Faculty of Engineering, \\ Shinshu University, 4-17-1 Wakasato, Nagano, 380-8553, Japan \\ $\S$ Technical Division, Faculty of Engineering, Shinshu University \\ 4-17-1 Wakasato, Nagano, 380-8553, Japan \\ *Corresponding author \\ Assistant Prof. Masahiro Shimizu \\ E-mail: shimizu@shinshu-u.ac.jp \\ Tel: +81-26-269-5627; Fax: +81-26-269-5627 \\ Prof. Susumu Arai \\ E-mail: araisun@shinshu-u.ac.jp \\ Tel: +81-26-269-5413; Fax: +81-26-269-5432
}

KEYWORDS: K-ion battery; Negative electrode; Tin oxide; Alloying/dealloying; Metal 


\section{ABSTRACT}

As one strategy for increasing energy density of K-ion batteries, electrochemical behavior of Sn oxides ( $\mathrm{SnO}$ and $\mathrm{SnO}_{2}$ ) was studied as a negative electrode material. X-ray photoelectron spectroscopy and X-ray diffraction revealed followings: SnO underwent phase separation at the first charge (reduction) process to form metallic Sn and potassium oxide, and reversible alloying reactions between the resulting Sn and K proceeded up to a composition of KSn or more. In contrast, $\mathrm{SnO}_{2}$ showed little electrochemical reactivity to potassium. Interestingly, a reversible capacity obtained from $\mathrm{SnO}$ electrode at the initial cycle was comparable to that of Sn alone electrode. SnO electrode exhibited a reversible capacity of $183 \mathrm{~mA} \mathrm{~h} \mathrm{~g}{ }^{-1}$ with a $80 \%$ capacity retention at the 30th cycle, whereas a capacity of Sn electrode rapidly decreased because of the electrode disintegration induced by the significant volume change during $\mathrm{K}-\mathrm{Sn}$ alloying/dealloying reactions. No crack and peeling off of an active material layer were confirmed in SnO electrode. Scanning transmission electron microscope image of the SnO electrode after the first cycle displayed that $\mathrm{Sn}$ nanoparticles were dispersed in amorphous-like $\mathrm{K}_{2} \mathrm{O}$ matrices. The reason for the improved cycle stability of $\mathrm{SnO}$ electrode is probably that $\mathrm{K}_{2} \mathrm{O}$ suppressed $\mathrm{Sn}$ aggregation and/or play a role as a buffer to volumetric change in Sn. For achieving a further long cycle life of SnO electrode, the optimization of particle size and electrolyte solution, and elemental substitution of part of oxygen would be effective. 


\section{INTRODUCTION}

Since the first commercialization of Li-ion battery (LIB) in 1991 by Sony Corp., the batteries have been equipped in most electric devices and the application has greatly widened to power supply for automobiles and storage of renewable energies. ${ }^{1}$ However, because the raw material of $\mathrm{Li}$ is localized in South America, the manufacturing always faces resources constraint. There is no doubt that the issue becomes more and more serious with the popularization of electric vehicles, and this is also the motivation for the development of Na-ion batteries (NIBs). ${ }^{2-6}$ Furthermore, recently, a rechargeable battery based on reversible uptake/release of $\mathrm{K}$ ion as the charge carrier has considered. Despite the larger size than Na ion, the electrochemical intercalation of $\mathrm{K}$ ion into graphite was demonstrated by Jian et al.: ex-situ XRD studies clarified that the formation of $\mathrm{KC}_{8}$ by stepwise potassiation from $\mathrm{KC}_{36}$ delivered a reversible capacity of $273 \mathrm{~mA}$ $\mathrm{h} \mathrm{g}^{-1} .^{7}$ The use of $\mathrm{K}$ ion with weaker Lewis acidity among the alkaline metal ions has the advantage of relatively high diffusion and facile charge transfer at an interface between electrode and electrolyte. ${ }^{8,9}$ In fact, Komaba et al. exhibited that a reversible capacity obtained at $0.1 C$ was maintained even at 15C. ${ }^{10,11}$ As discussed and examined in LIB and NIB studies, electrochemical potassiation/depotassiation reactions of group 14 elements are also very interesting. ${ }^{12}$ On the basis of $\mathrm{K}-\mathrm{Sn}$ phase diagram ${ }^{13}$, a most K-rich binary phase is $\mathrm{K}_{2} \mathrm{Sn}$ which can lead to a theoretical capacity of $452 \mathrm{~mA} \mathrm{~h} \mathrm{~g}^{-1}$ more than that of graphite (KC 8 : $\left.279 \mathrm{~mA} \mathrm{~h} \mathrm{~g}{ }^{-1}\right)$. It has been reported that $\mathrm{Sn}$ is electrochemically capable of reacting with $\mathrm{K}$ at the potential of $0.2 \mathrm{~V} \mathrm{vs} . \mathrm{K} / \mathrm{K}^{+}$and shows a depotassiation capacity of $245 \mathrm{~mA} \mathrm{~h} \mathrm{~g}^{-1} \cdot{ }^{14}$ Although it seems to be disadvantageous in terms of capacity per weight, it is rather advantageous from the viewpoint of volume $\left(\mathrm{K}_{2} \mathrm{Sn}: 3261 \mathrm{~mA} \mathrm{~h}\right.$ $\left.\mathrm{cm}^{-3}\right) .{ }^{15}$ There is, however, concerned about cycle stability in a Sn electrode. The relatively large volume expansion/contraction (KSn: 200\%) ${ }^{14}$ associated with K-Sn alloying/dealloying 
reactions is one of the causes which triggers an electrical isolation of active material involved in poor cycling performance. $\mathrm{SnO}$ and $\mathrm{SnO}_{2}$ as negative electrode materials for LIBs and NIBs undergo phase separation to form metallic Sn and alkali metal oxide $\left(M_{2} \mathrm{O}, M=\mathrm{Li}, \mathrm{Na}\right)$ at an initial charge process. ${ }^{16,17}$ In the subsequent cycles, the oxide matrix suppresses aggregation of Sn and reduces mechanical stress induced by volume change in Sn. As a result, Sn-based oxide electrodes show higher cyclability than a $\mathrm{Sn}$ electrode. In addition, as for $\mathrm{SnO}_{2}$, a higher capacity than $\mathrm{Sn}$ alone can be expected by the following conversion reactions: ${ }^{18,19}$

$$
\begin{aligned}
& \mathrm{SnO}_{2}+4 M+4 \mathrm{e}^{-} \leftrightarrow \mathrm{Sn}+2 M_{2} \mathrm{O} \\
& \mathrm{Sn}+x M+x \mathrm{e}^{-} \leftrightarrow M_{x} \mathrm{Sn}
\end{aligned}
$$

Here, we report electrochemical reactivity of $\mathrm{SnO}$ and $\mathrm{SnO}_{2}$ with $\mathrm{K}$, and discuss the reaction mechanism by the results of XPS analyses, ex-situ X-ray diffraction, ex-situ Raman scattering, and STEM observation. To the best of our knowledge, this is the first report on K-insertion/extraction of $\mathrm{SnO}$.

\section{EXPERIMENTAL SECTION}

$\mathrm{SnO}$ and $\mathrm{SnO}_{2}$ particles were synthesized by a precipitation method. First, a solution including $\mathrm{SnCl}_{2} \cdot 2 \mathrm{H}_{2} \mathrm{O}(15 \mathrm{~g})$ and $\mathrm{HCl}(15 \mathrm{~g})$ was diluted by deionized water $(15 \mathrm{~mL})$. Then, the solution was dropped into deionized water $\left(500 \mathrm{~mL}, 90^{\circ} \mathrm{C}\right)$ while adjusting $\mathrm{pH} 5$ using $\mathrm{NaOH}(5$ mol $\mathrm{dm}^{-3} / \mathrm{M}$ ). After further stirring for $10 \mathrm{~min}$, $\mathrm{HCl}$ was added so as to $\mathrm{pH}$ 3. The resulting suspension was filtered and washed with deionized water. The washed precipitates were dried under vacuum at $110{ }^{\circ} \mathrm{C}$ for $12 \mathrm{~h}$. Further oxidation by heat treatment at $900{ }^{\circ} \mathrm{C}$ for $2 \mathrm{~h}$ was conducted to obtain $\mathrm{SnO}_{2}$ particle. Particle shape was observed by field-emission scanning electron microscopy (FE-SEM; JSM-7000F, JEOL Co., Ltd.), field-emission transmission electron 
microscopy (TEM, JEM-2010, JEOL Co., Ltd.), and scanning transmission electron microscopy (STEM; HD2300A, Hitachi). Acetylene black (AB) and carboxymethyl cellulose (CMC, $\left.\mathrm{M}_{\mathrm{w}}=90,000\right)$ and styrene butadiene rubber (SBR) were used as the conductive additive and the binder for preparation of slurry-type electrodes. The weight ratio of active material/AB/CMC/SBR was 70/15/10/5 wt. \%. A glass fiber filter (thickness: $260 \mu \mathrm{m}$, Whatman GF/A) soaked in an organic electrolyte was used as the separator. Alkaline-salts of lithium hexafluorophosphate ( $\left.\mathrm{LiPF}_{6}\right)$, sodium hexafluorophosphate $\left(\mathrm{NaPF}_{6}\right)$, and potassium hexafluorophosphate $\left(\mathrm{KPF}_{6}\right)$ were dissolved in ethylene carbonate (EC) and diethyl carbonate (DEC) with a volume ratio of 50/50. Electrochemical reactivities of $\mathrm{SnO}$ and $\mathrm{SnO}_{2}$ with potassium were studied by galvanostatic charge-discharge cycling test with 2032-type coin cells and cyclic voltammetry measurements with three-electrode cells at $25^{\circ} \mathrm{C}$. For comparison, Sn powder with a diameter of $70-500 \mathrm{~nm}$ was used. ${ }^{6}$ Reaction mechanism was investigated by means of ex-situ X-ray diffraction (XRD, SmartLab; Rigaku) with CuKa radiation, ex-situ Raman spectroscopy (T64000; HORIBA, Ltd.), and X-ray photoelectron spectroscopy (XPS; PHI Quantera II ${ }^{\mathrm{TM}}$, ULVAC-PHI, Inc.) with an Xray (monochromatic radiation $\mathrm{Al}-\mathrm{K} \alpha$ ) beam diameter of $100 \mu \mathrm{m}$ operated at $25 \mathrm{~W}$. XPS spectra were calibrated using the binding energy of hydrocarbon $(\mathrm{C}-\mathrm{C}, \mathrm{C}-\mathrm{H}$ groups $)$ at $284.6 \mathrm{eV}$. The measurement was conducted without transfer vessel.

\section{RESULTS AND DISCUSSION}

XRD patterns of precipitations before and after heat treatment were good agreement with $\mathrm{SnO}$ with a tetragonal system (space group: P4/nmm/ICSD: 01-072-0836) and $\mathrm{SnO}_{2}$ with a tetragonal system (space group: P42/mnm/ICSD: 00-041-1445), which means that the target compounds were successfully synthesized without any impurity (Figure 1). In view of the color as 
displayed in photographs, phase transition from monoxide to dioxide was observed. SnO particle has a flower-like morphology with a $10 \mu \mathrm{m}$ diameter. The thickness of sheet forming a secondary particle is $c a .100 \mathrm{~nm}$. The size and morphology of $\mathrm{SnO}_{2}$ particle obtained by heat treatment showed almost no change.
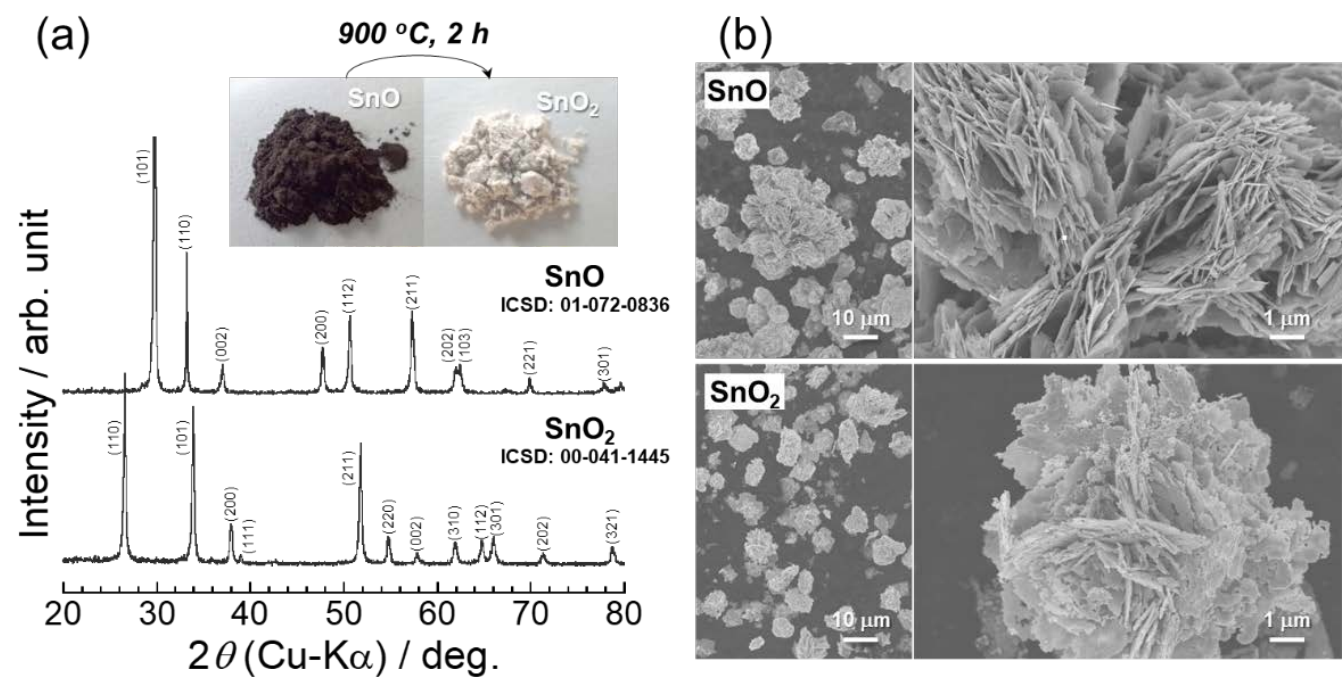

Figure 1. (a) XRD patterns and (b) FE-SEM images of synthesized $\mathrm{SnO}$ and $\mathrm{SnO}_{2}$ particles by a precipitation method. Inset: photographs of precipitation before and after heat treatment at $900{ }^{\circ} \mathrm{C}$ for $2 \mathrm{~h}$.

Figure 2 exhibits electrochemical K-insertion/extraction behavior of $\mathrm{Sn}, \mathrm{SnO}$, and $\mathrm{SnO}_{2}$ electrodes. Given the reaction mechanisms as LIBs and NIBs negative electrodes (Figure S1, Supporting Information), it is thought that Sn oxide undergoes phase separation by reduction at the first cycle to form metallic Sn and reversible K-Sn alloying/dealloying takes place at following cycles. In metallurgical synthesis ${ }^{13}$, the most K-rich alloy phase is $\mathrm{K}_{2} \mathrm{Sn}$, and the theoretical capacity is $452 \mathrm{~mA} \mathrm{~h} \mathrm{~g}$.- . However, many literatures have reported that electrochemical alloying 
reactions progress only up to KSn phase (226 mA h g $\left.{ }^{-1}, 1631 \mathrm{~mA} \mathrm{~h} \mathrm{~cm}^{-3}\right)$ via $\mathrm{K}_{4} \mathrm{Sn}_{23}$, $\mathrm{K}_{4} \mathrm{Sn}_{9}$, and $\mathrm{K}_{2} \mathrm{Sn}_{5}$ phases. ${ }^{14,20,21}$ As shown in charge/discharge curves under a constant current condition (Figure 2a), Sn electrode delivered an initial reversible capacity of $229 \mathrm{~mA} \mathrm{~h} \mathrm{~g}{ }^{-1}$ with a low Coulombic efficiency of 63\%. The initial potassiation curve of the Sn electrode are composed of three voltage plateaus of $0.5-0.235 \mathrm{~V}, 0.235-0.17 \mathrm{~V}$, and $0.17-0.005 \mathrm{~V}$ (vs. $\mathrm{K} / \mathrm{K}^{+}$). Excluding an irreversible capacity ( $25 \mathrm{~mA} \mathrm{~h} \mathrm{~g}^{-1}$ ) involved in electrolyte decomposition, the voltage plateau up to $0.17 \mathrm{~V}\left(\sim 252 \mathrm{~mA} \mathrm{~h} \mathrm{~g}^{-1}\right)$ corresponds to the uptake of $1 \mathrm{~mol} \mathrm{~K}$ per $\mathrm{Sn}$, which is good agreement with a theoretical capacity of KSn alloy phase. On the other hand, Tang et al. verified the formation of $\mathrm{K}_{2} \mathrm{Sn}$ at the charge state. ${ }^{15} \mathrm{In}$ addition, because a capacity of $\mathrm{K}-\mathrm{Sn}$ alloying estimated from a voltage region below $0.5 \mathrm{~V}$ is beyond a theoretical capacity of $\mathrm{KSn}\left(226 \mathrm{~mA} \mathrm{~h} \mathrm{~g}^{-1}\right)$, the voltage plateau between 0.17 and $0.005 \mathrm{~V}$ is presumably attributed to an alloying reaction toward $\mathrm{K}_{2} \mathrm{Sn}$. We investigated an electrochemical property of acetylene black (AB) which was used as a conductive additive in the present study (Figure S2, Supporting Information). AB electrode showed initial charge and discharge capacities of 358 and $139 \mathrm{~mA} \mathrm{~h} \mathrm{~g}^{-1}$, respectively. The poor efficiency comes from the formation of surface layer involved in electrolyte decomposition. Even considering an irreversible capacity based on the content of AB in composite electrode (15 wt.\%), it cannot explain that the decomposition electrolyte alone is not responsible for the low Coulombic efficiency of the Sn electrode. We therefore concluded that the low reversibility of the Sn electrode was mainly due to the electrode disintegration. As for SnO electrode in the first cycle, charge and discharge capacities were 430 and $229 \mathrm{~mA} \mathrm{~h} \mathrm{~g}$, respectively. Assuming that the alloying/dealloying reactions between metallic Sn and K is dominant in the main capacity of the $\mathrm{SnO}$ electrode, $\mathrm{K}-\mathrm{Sn}$ alloying reactions do not proceed without the reduction of $\mathrm{SnO}$.

$$
\mathrm{SnO}+2 \mathrm{~K}^{+}+2 \mathrm{e}^{-} \leftrightarrow \mathrm{Sn}+\mathrm{K}_{2} \mathrm{O}
$$




$$
\mathrm{Sn}+x \mathrm{~K}^{+}+x \mathrm{e}^{-} \leftrightarrow \mathrm{K}_{x} \mathrm{Sn}
$$

The theoretical capacity of the equation (3) is $398 \mathrm{~mA} \mathrm{~h} \mathrm{~g}^{-1}$. In the initial charge curve of SnO electrode, major two voltage plateaus were confirmed at $0.45-0.26 \mathrm{~V}$ and $0.26-0.005 \mathrm{~V}$ (vs. $\mathrm{K} / \mathrm{K}^{+}$). Since the former plateau was higher than that observed in Sn electrode and was not recognized after the second cycle, the plateau can be assigned to the reduction of $\mathrm{SnO}$ to form potassium oxide $\left(\mathrm{K}_{2} \mathrm{O}\right)$ and metallic Sn, and the corresponding capacity was approximately $200 \mathrm{~mA} \mathrm{~h} \mathrm{~g}{ }^{-1}$. Based on the capacity, it is considered that the equation (3) proceeded by only 50\%. In that case, only 44 wt.\% of metallic Sn is present in SnO electrode, and apparent theoretical capacities of SnO are 100 and $200 \mathrm{~mA} \mathrm{~h} \mathrm{~g}{ }^{-1}$ when $\mathrm{KSn}$ and $\mathrm{K}_{2} \mathrm{Sn}$ are formed, respectively. The lower voltage plateau between $0.26-0.005 \mathrm{~V}$ has a capacity of $200 \mathrm{~mA} \mathrm{~h} \mathrm{~g}^{-1}$ which is identical to the apparent theoretical capacity of the formation of $\mathrm{K}_{2} \mathrm{Sn}$ in $\mathrm{SnO}$ electrode. $\mathrm{K}_{2} \mathrm{Sn}$ is formed and even if potassium can be completely released from the alloy phase, it is still insufficient for the reversible capacity (229 mA $\mathrm{h} \mathrm{g}^{-1}$ ) obtained at the first cycle. We conducted charge-discharge test of $\mathrm{SnO}$ electrode in the voltage range of $0.28-2.00 \mathrm{~V}\left(\mathrm{vs} . \mathrm{K} / \mathrm{K}^{+}\right.$), as an additional experiment to ascertain whether a conversion reaction of the equation (3) occurred reversibly or not (Figure S3, Supporting Information). In the voltage range without $\mathrm{K}-\mathrm{Sn}$ alloying reactions, an initial reversible capacity of $67 \mathrm{~mA} \mathrm{~h} \mathrm{~g}^{-1}$ was obtained and the capacity gradually decreased. The result indicates that the conversion reaction (oxidation) slightly took place in $\mathrm{SnO}$ electrode. Comparing cyclic voltammograms (Figure 2b), the two anodic potential peaks (1.03 V and 1.44 V) related to stepwise K-extraction from $\mathrm{K}-\mathrm{Sn}$ intermetallic compounds in $\mathrm{SnO}$ electrode were higher than those of $\mathrm{Sn}$ electrode $(0.79 \mathrm{~V}$ and $1.13 \mathrm{~V}) . \mathrm{K}_{2} \mathrm{O}$ matrix generated in the first reduction cycle is probably responsible for the overpotential. In contrast to $\mathrm{Sn}$ and $\mathrm{SnO}$ electrodes, $\mathrm{SnO}_{2}$ showed a little electrochemical reactivity against potassium; there was only a reversible capacity of $32 \mathrm{~mA} \mathrm{~h} \mathrm{~g}^{-1}$ 
at the first and second cycle. This is also supported from the results of XPS spectra (Figure 3). Sn component existed as a tetravalent $\left(\mathrm{Sn}^{4+}\right)$ species before and after charge/discharge. This is probably because of a poor electrical conductivity and a relatively large particle size. Even with change in upper cut-off voltage from 2.0 to $3.0 \mathrm{~V}$ and the use of submicron sized particle, a reversible capacity did not significantly increase (Figure S4, Supporting Information). Miniaturization to nanometer order and improvement of electrical conductivity by metal doping have the potential to enhance the reactivity of $\mathrm{SnO}_{2}$, and thereby should lead a high capacity by alloying/dealloying as well as conversion reactions. ${ }^{22,23}$ On the other hand, in $\mathrm{SnO}$ electrode, $\mathrm{Sn}^{(0)}$ (metallic Sn) and $\mathrm{K}-\mathrm{O}$ bond were detected after discharged state (Figure S5, Supporting Information). The detection of $\mathrm{Sn}^{2+}$ and $\mathrm{Sn}^{4+}$ after discharged state at $2.000 \mathrm{~V}$ implies unreacted $\mathrm{SnO}$ and $\mathrm{SnO}_{2}$ formed by partially occurred conversion reaction and surface oxidation of Sn. We tried to directly identify the reaction mechanism by XRD analysis. 
(a)

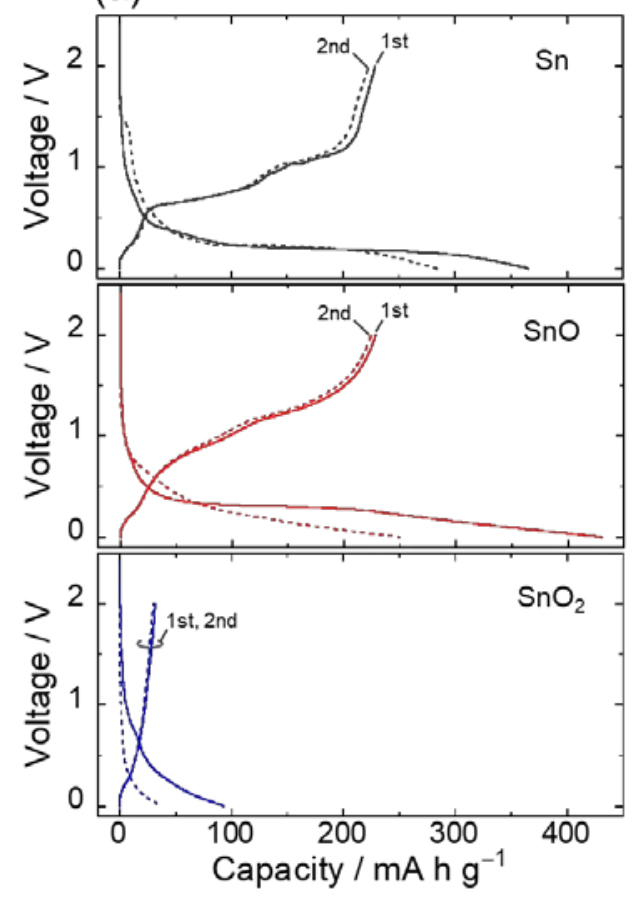

(b)

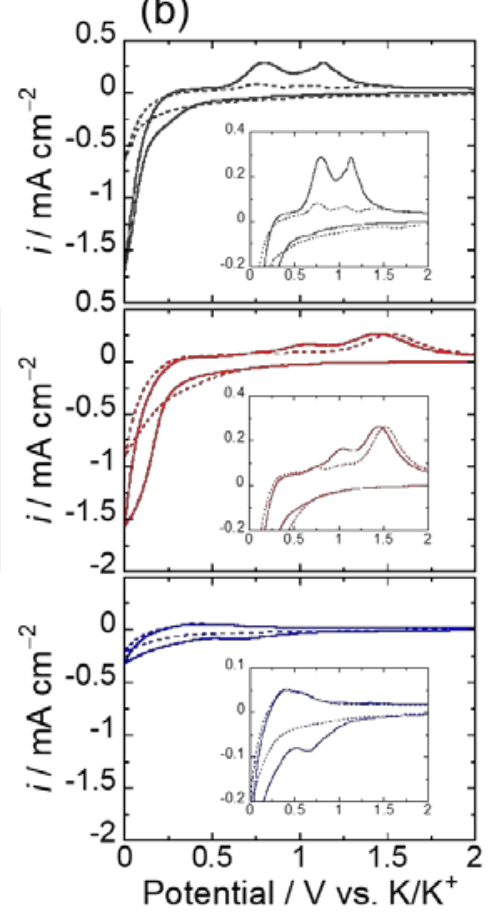

Figure 2. (a) Initial charge-discharge (K-insertion/extraction) profiles and (b) cyclic voltammograms of Sn-based electrodes in $0.5 \mathrm{M} \mathrm{KPF}_{6} / \mathrm{EC}$ :DEC. Current density and sweep rate were set to $25 \mathrm{~mA} \mathrm{~g}^{-1}$ and $1 \mathrm{mV} \mathrm{s}^{-1}$, respectively. 
(a) $\mathrm{SnO}$

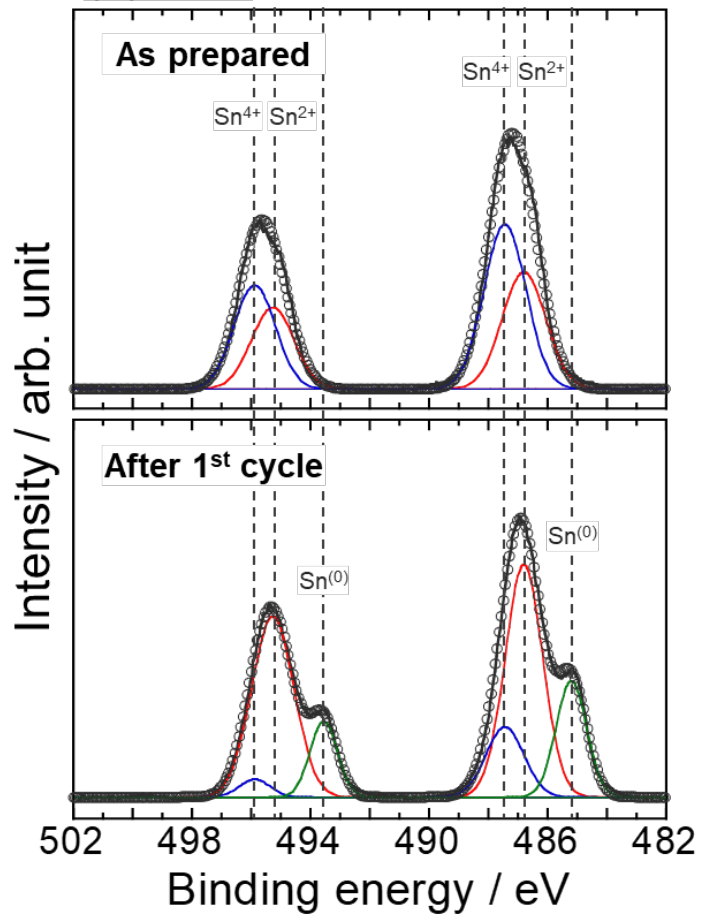

(b) $\mathrm{SnO}_{2}$

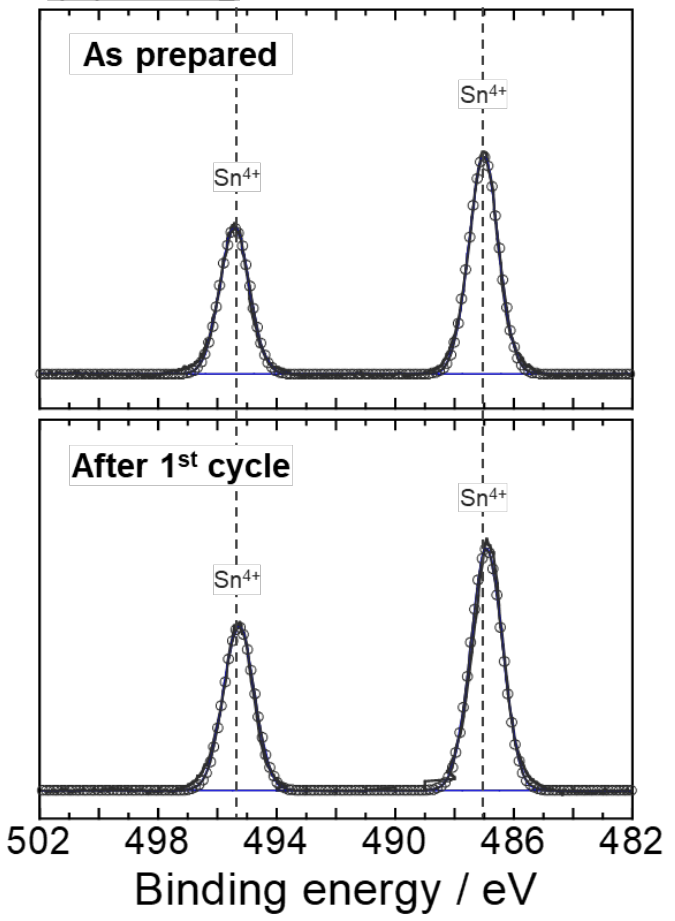

Figure 3. XPS spectra of $\mathrm{Sn} 3 \mathrm{~d}$ region for (a) $\mathrm{SnO}$ and (b) $\mathrm{SnO}_{2}$ electrodes before and after the first depotassiation cycle $\left(2.0 \mathrm{~V}\right.$ vs. $\left.\mathrm{K} / \mathrm{K}^{+}\right)$. An incident $\mathrm{X}$-ray source is monochromatic radiation (Al-Ka, $1486.6 \mathrm{eV}$ ) and was operated at $25 \mathrm{~W}$ (X-ray beam diameter: $100 \mu \mathrm{m}$, source analyzer angle: $\left.45.0^{\circ}\right)$.

Figure 4 shows ex-situ XRD patterns of $\mathrm{SnO}$ and $\mathrm{SnO}_{2}$ electrodes at the cutoff voltages of $0.005 \mathrm{~V}$ and $2.000 \mathrm{~V}$. The presumable alloy phase in SnO electrode under fully reduced condition of $0.005 \mathrm{~V}$ is $\mathrm{KSn}$ and/or $\mathrm{K}_{2} \mathrm{Sn}$. Although diffraction peaks of $\mathrm{SnO}$ completely disappeared, a peak associated with $\mathrm{K}-\mathrm{Sn}$ phase was only $\mathrm{K}_{4} \mathrm{Sn}_{23}$ with a cubic system (ICSD: 03-065-3351). The content K per Sn was much lower than that of the expected phase. In view from an initial reversible capacity of SnO electrode, the alloy phase should yield to at least KSn or more. This is because considerably low atomic scattering factor of potassium of $\mathrm{K}-\mathrm{Sn}$ alloys. ${ }^{20}$ Although we covered with charged SnO electrode by kapton film to prevent an air exposure, we cannot completely deny 
the possibility of phase separation of $\mathrm{K}-\mathrm{Sn}$ alloys formed at $0.005 \mathrm{~V}$ by an air exposure. At the fully oxidized condition of $2.000 \mathrm{~V}$, no reformation of $\mathrm{SnO}$ was confirmed, and the presence of metallic Sn was dominant, which revealed that the conversion reaction hardly occurred in the case of the present experimental condition (upper cut-off voltage: $2.0 \mathrm{~V}$ ). In addition, even in the cutoff voltage of $3.000 \mathrm{~V}$, the complete reformation of $\mathrm{SnO}$ was not recognized from XRD pattern (not shown here). In $\mathrm{SnO}_{2}$ electrode, there was no change in composition irrespective to charge/discharge state, which is good agreement with the XPS and Raman measurement results (Figure S6, Supporting Information). In other words, $\mathrm{SnO}_{2}$ is basically electrochemical inactive to potassium or cannot be completely reduced to Sn. Therefore, the obtained reversible capacity is presumably due to pseudo capacitive.

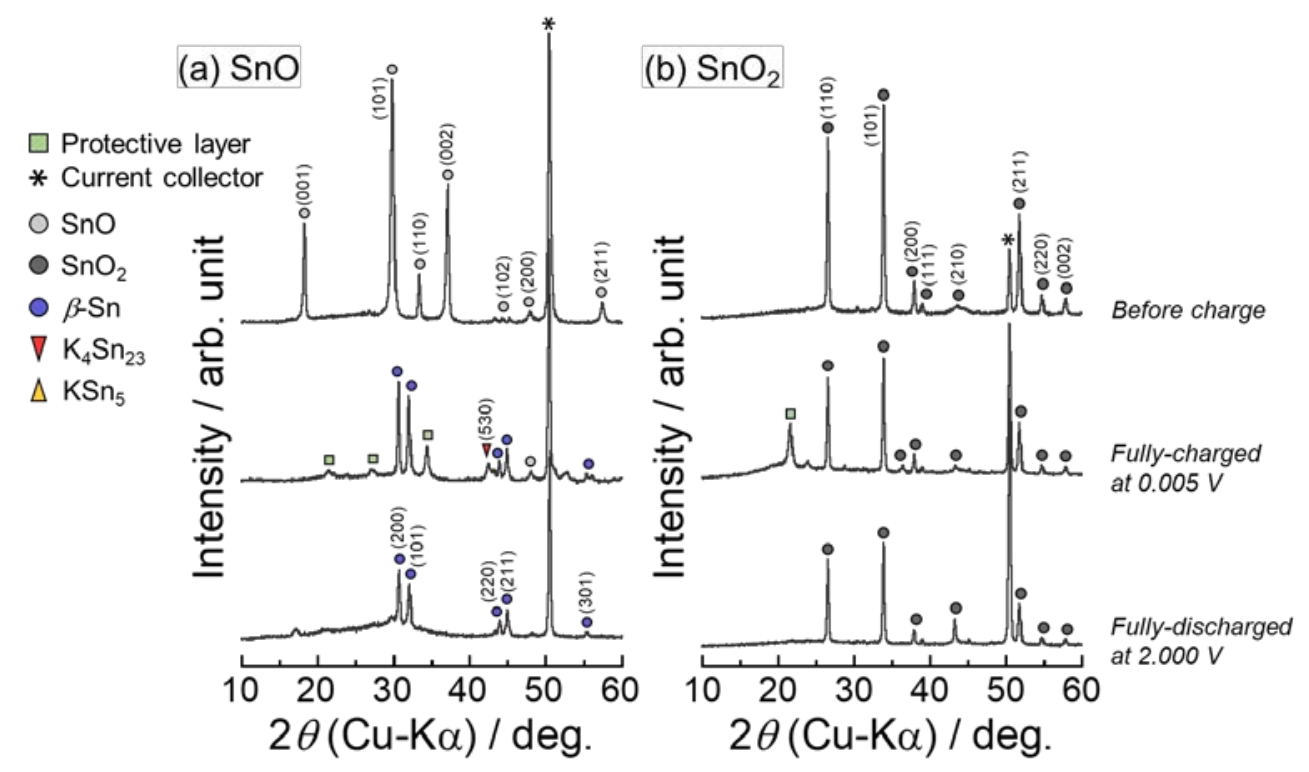

Figure 4. XRD patterns of (a) $\mathrm{SnO}$ and (b) $\mathrm{SnO}_{2}$ electrodes during the first potassiuminsertion cycle. SnO undergoes phase separation to form metallic Sn. 
Transmission electron microscopy was used to visually understand the reaction mechanism (Figure 5). In a highly magnified TEM image of SnO particle before cycling, clear lattice fringes with a $d$-spacing of $0.254 \mathrm{~nm}$ assigned to a (110) plane of $\mathrm{SnO}$ with a tetragonal system were confirmed. Although we could not observe the lattice fringe after the first depotassiation, a low magnification HAADF image of sliced $\mathrm{SnO}$ electrode using ion milling indicates that $\mathrm{Sn}$ nanoparticles with $c a .10 \mathrm{~nm}$-diameter appear to be dispersed in amorphous-like $\mathrm{K}_{2} \mathrm{O}$ oxide matrix formed at the first cycle (Figures S7, S8, and S9 Supporting Information). In the STEM-EDS line profile, the intensity for Sn element corresponds to not $\mathrm{C}$ element but to that for $\mathrm{O}$ and $\mathrm{K}$ elements, which is not direct, but strongly supports that $\mathrm{Sn}$ nanoparticles are dispersed into $\mathrm{K}_{2} \mathrm{O}$ matrix. 


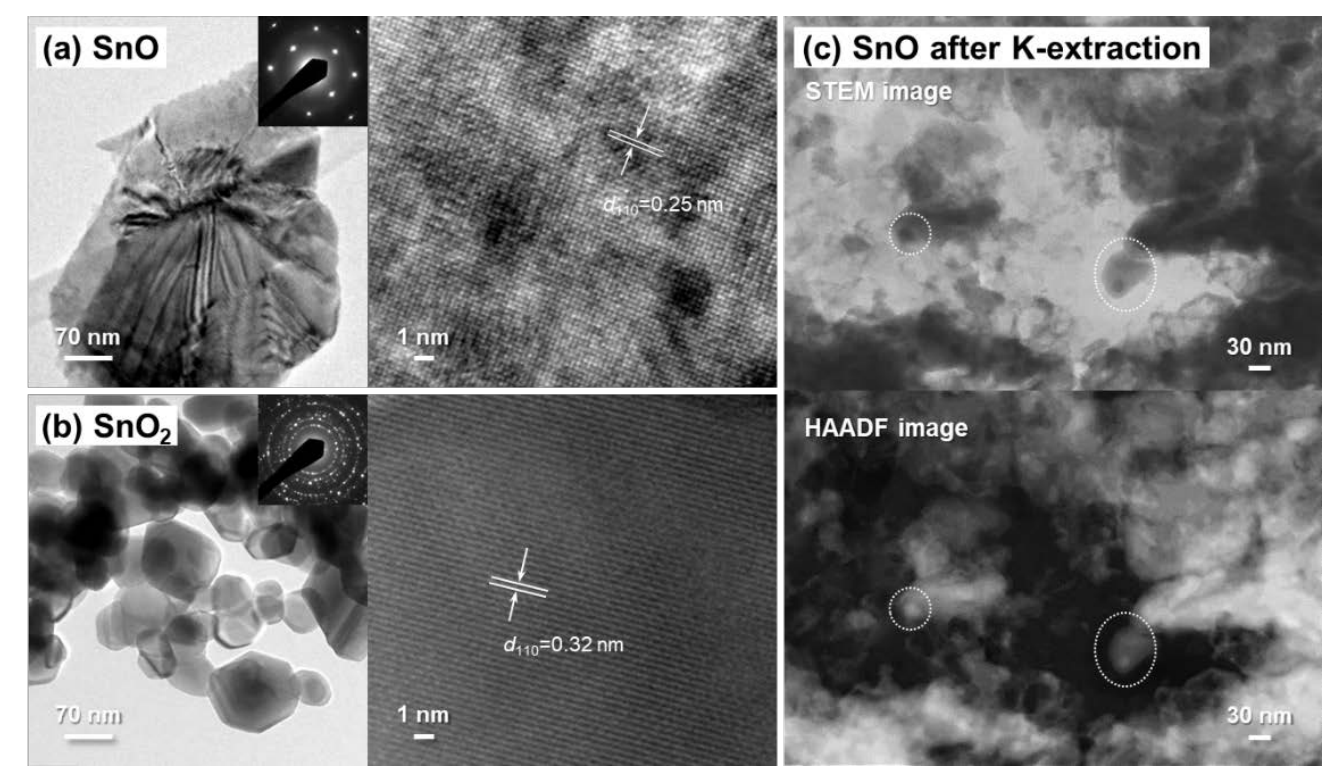

Figure 5. TEM images and SAED patterns of (a) $\mathrm{SnO}$ and (b) $\mathrm{SnO}_{2}$ powder, and STEM and HAADF images of (c) SnO electrode after the first depotassiation. Sn crystalline in nanoparticles were dispersed in amorphous-like oxide matrix.

Figure 6 represents cycling performance of Sn-based electrodes in $0.5 \mathrm{M} \mathrm{KPF}_{6} / \mathrm{EC}: \mathrm{DEC}$ (50:50 vol.\%). Sn electrode showed a rapid capacity fading with a decrease in Coulombic efficiency by 10 cycles, and only a capacity of $19 \mathrm{~mA} \mathrm{~h} \mathrm{~g}^{-1}$ remained after 50th cycle with an extremely low retention of $8 \%$. The theoretical capacity of fully potassiated $\mathrm{Sn}\left(\mathrm{K}_{2} \mathrm{Sn}\right)$ is lower than those of $\mathrm{Li}_{4.4} \mathrm{Sn}\left(990 \mathrm{~mA} \mathrm{~h} \mathrm{~g}^{-1}, \Delta 260 \%\right)$ and $\mathrm{Na}_{3.75} \mathrm{Sn}\left(847 \mathrm{~mA} \mathrm{~h} \mathrm{~g}^{-1}, \Delta 420 \%\right)$ as negative electrodes for LIBs and NIBs. Nevertheless, the volume change ratio in Sn during potassiation is relatively high for the capacities because of large ionic radii (Shannon’s ionic radii $\mathrm{Li}^{+} / 76 \mathrm{pm}$, $\mathrm{Na}^{+} / 102 \mathrm{pm}, \mathrm{K}^{+} / 138 \mathrm{pm}$ ) (Figure S10, Supporting Information). The severe volumetric change suffered from the large ion size was remarkable in cross-sectional FE-SEM image of Sn electrode after cycling (Figure 7): the electrode was regarded to be quite different from the original form, 
and great cracks and detachment of an active material layer (electrical isolation) leading to capacity loss was confirmed. This is probably the reason why the Coulombic efficiency suddenly decayed. On the other hand, up to the 30th cycle, SnO electrode remained a high capacity of $183 \mathrm{~mA} \mathrm{~h} \mathrm{~g}^{-1}$ which was $80 \%$ of the initial capacity. In fact, no crack and peel-off were observed after cycling (Figure S11, Supporting Information). The good performance clearly shows the effect of $\mathrm{K}_{2} \mathrm{O}$ matrix generated at the first reduction process, and it is considered that $\mathrm{K}_{2} \mathrm{O}$ functions to suppress aggregation of Sn during the discharge process and/or to release stress induced by $\mathrm{K}-\mathrm{Sn}$ alloying/dealloying reactions. However, Sn seemed to aggregate to form micrometer-order particles, which is the cause of capacity decline between the 30th and the 50th cycles. Although we tried to enhance the electrode performance by adding 5 vol.\% fluoroethylene carbonate (FEC) which is a typical improver, the performance was deteriorated rather (Figure S12, Supporting Information). Meanwhile, a capacity of $\mathrm{SnO}_{2}$ remained small and hardly changed. To realize a further cycle stability of SnO electrode, the optimization of particle size and electrolyte solution and elemental substitution of part of oxygen would be effective. 


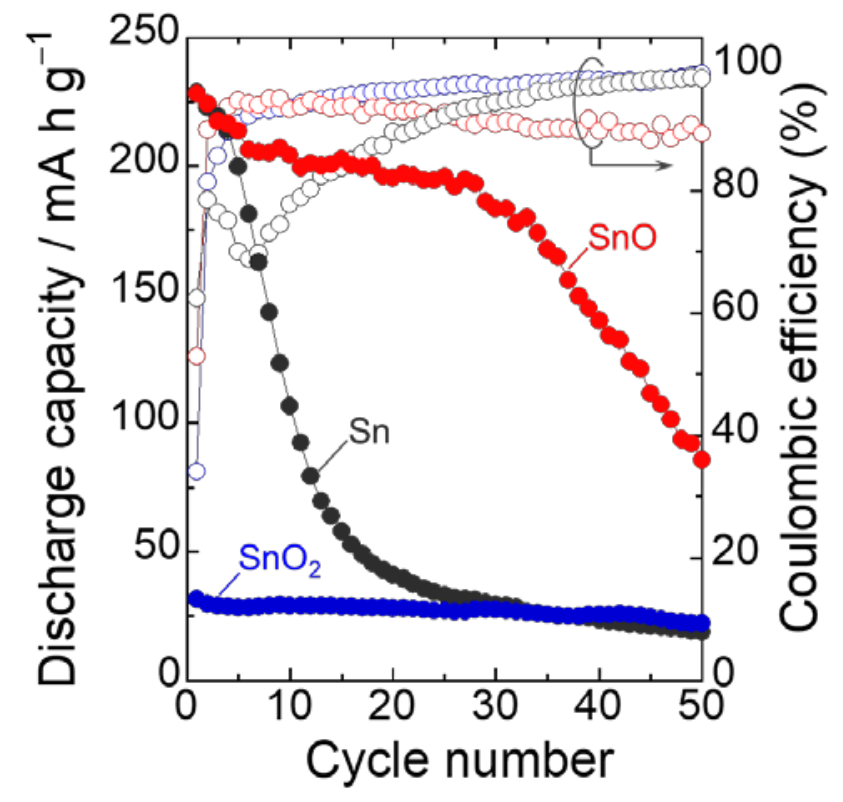

Figure 6. Dependence of discharge capacities (closed) and Coulombic efficiency (circle) on cycle number for $\mathrm{Sn}, \mathrm{SnO}$, and $\mathrm{SnO}_{2}$ electrodes in $0.5 \mathrm{M} \mathrm{KPF}_{6} / \mathrm{EC}$ :DEC. The loading mass of active material is $c a .0 .8 \mathrm{mg} \mathrm{cm}^{-2}$. 

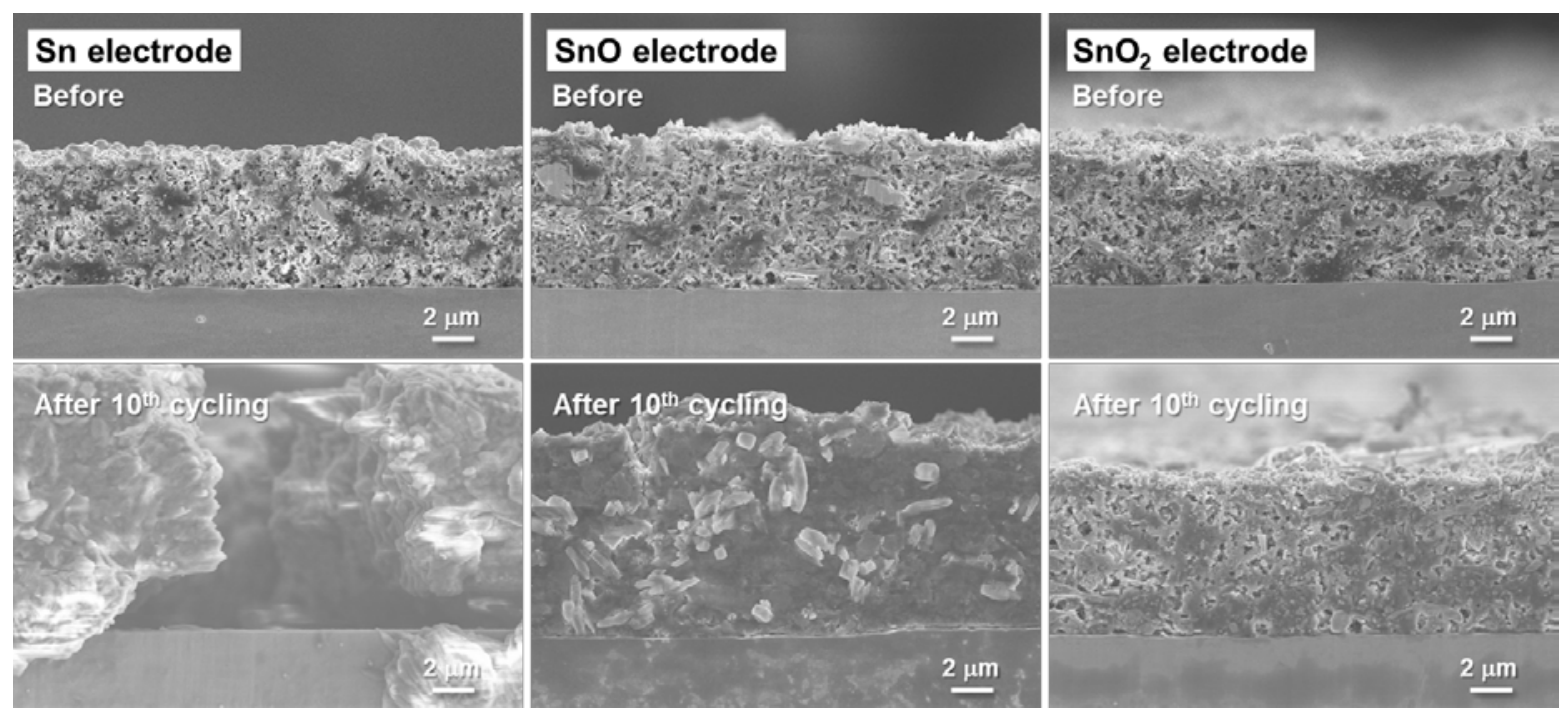

Figure 7. Cross-sectional FE-SEM images of Sn-based electrodes before and after the 10th cycle under constant current density of $25 \mathrm{~mA} \mathrm{~g}^{-1}$. The thickness of the Sn electrode expanded twice as much as the original thickness, and significant electrode disintegration was observed. In contrast, in the SnO electrode, collapse such as the generation of cracks was not recognized.

\section{CONCLUSIONS}

$\mathrm{SnO}$ and $\mathrm{SnO}_{2}$ powders were synthesized by a precipitation method and electrochemical potassiation and depotassiation properties were examined using constant current charge/discharge tests. We demonstrated for the first time that metallic Sn formed in the first reduction process on SnO electrode reversibly absorbed and released with $\mathrm{K}$ to exhibit a reversible capacity of about $230 \mathrm{~mA} \mathrm{~h} \mathrm{~g}^{-1}$ which is comparable to that of Sn electrode. It was found that conversion reactions involved in re-transformation of SnO hardly takes place under the upper cut-off voltage of 2.0 and 3.0 V. In Sn electrode, the detachment of active material layer related to rapid capacity fading was observed. In contrast, SnO electrode remained a reversible capacity of $183 \mathrm{~mA} \mathrm{~h} \mathrm{~g}^{-1}$ even after the 30th cycle, and remarkable electrode disintegration such as formation of crack and exfoliation was 
not recognized though the electrode thickness slightly increased. The favorable performance is because $\mathrm{K}_{2} \mathrm{O}$ matrix irreversibly formed at the first cycle suppressed the aggregation of $\mathrm{Sn}$ nanoparticles or acted as a buffer to release a stress induced by large volumetric change in Sn.

\section{ASSOCIATED CONTENT}

\section{Supporting information.}

The following file is available free of charge.

Electrochemical $\mathrm{Li}$-, Na-insertion/extraction properties of $\mathrm{SnO}$ and $\mathrm{SnO}_{2}$ electrodes. Charge-discharge curves of AB electrode. STEM images, FE-SEM images, Raman spectra, and XPS spectra of Sn-based electrode before and after cycling.

\section{AUTHOR INFORMATION}

\section{Corresponding Author:}

*Masahiro Shimizu, E-mail: shimizu@shinshu-u.ac.jp; Tel: +81-26-269-5627; Fax: +81-26-2695627. *Prof. Susumu Arai, E-mail: araisun@shinshu-u.ac.jp; Tel: +81-26-269-5413; Fax: +8126-269-5432.

\section{ACKNOWLEDGMENTS}

This work was supported by Early-Career Scientists (18K14317) and Grant-in-Aid for Research Activity Start-up (16H06838) from the Japan Society for the Promotion of Science (JSPS). M. Shimizu gratefully acknowledges Ms. Tedra Elliot for her advice. 


\section{REFERENCES}

(1) Chu, S.; Majumdar, A., Opportunities and Challenges for a Sustainable Energy Future. Nature 2012, 488, 294-303.

(2) Komaba, S.; Murata, W.; Ishikawa, T.; Yabuuchi, N.; Ozeki, T.; Nakayama, T.; Ogata, A.; Gotoh, K.; Fujiwara, K., Electrochemical Na Insertion and Solid Electrolyte Interphase for Hard-Carbon Electrodes and Application to Na-Ion Batteries. Adv. Funct. Mater. 2011, 21, 3859-3867.

(3) Stevens, D. A.; Dahn, J. R., High Capacity Anode Materials for Rechargeable Sodium-Ion Batteries. J. Electrochem. Soc. 2000, 147, 1271-1273.

(4) Xia, X.; Obrovac, M. N.; Dahn, J. R., Comparison of the Reactivity of $\mathrm{Na}_{\mathrm{x}} \mathrm{C} 6$ and $\mathrm{Li}_{\mathrm{x}} \mathrm{C6}$ with Non-Aqueous Solvents and Electrolytes. Electrochem. Solid-State Lett. 2011, 14, A130-A133.

(5) Shimizu, M.; Tsushima, Y.; Arai, S., Electrochemical Na-Insertion/Extraction Property of NiCoated Black Phosphorus Prepared by an Electroless Deposition Method. ACS Omega 2017, 2, 4306-4315.

(6) Shimizu, M.; Yatsuzuka, R.; Horita, M.; Yamamoto, T.; Arai, S., Design of Roughened Current Collector by Bottom-up Approach Using the Electroplating Technique: ChargeDischarge Performance of a Sn Negative-Electrode for Na-Ion Batteries. J. Phys. Chem. C 2017, 121, 27285-27294.

(7) Jian, Z.; Luo, W.; Ji, X., Carbon Electrodes for K-Ion Batteries. J. Am. Chem. Soc. 2015, 137, 11566-11569.

(8) Marcus, Y. Thermodynamic functions of transfer of single ions from water to nonaqueous and mixed solvents: Part 3 - Standard potentials of selected electrodes. Pure Appl. Chem. 1985, 57, 1129-1132.

(9) Okoshi, M.; Yamada, Y.; Komaba, S.; Yamada, A.; Nakai, H. Theoretical Analysis of Interactions between Potassium Ions and Organic Electrolyte Solvents: A Comparison with Lithium, Sodium, and Magnesium Ions. J. Electrochem. Soc. 2017, 164, A54-A60.

(10)Komaba, S.; Hasegawa, T.; Dahbi, M.; Kubota, K., Potassium Intercalation into Graphite to Realize High-Voltage/High-Power Potassium-Ion Batteries and Potassium-Ion Capacitors. Electrochem. Commun. 2015, 60, 172-175.

(11)Kubota, K.; Dahbi, M.; Hosaka, T.; Kumakura, S.; Komaba, S., Towards K-Ion and Na-Ion Batteries as "Beyond Li-Ion". Chem. Rec. 2018, 18, 1-22. 
(12) Sultana, I.; Rahman, M. M.; Chen, Y.; Glushenkov, A. M., Potassium-Ion Battery Anode Materials Operating through the Alloying-Dealloying Reaction Mechanism. Adv. Funct. Mater. 2017, 28, 1703857.

(13) Sangster, J.; Bale, C.W., The K-Sn (Potassium-Tin) System, J. Phase Equilib. 1998, 19, 67-69.

(14) Ramireddy, T.; Kali, R.; Jangid, M. K.; Srihari, V.; Poswal, H. K.; Mukhopadhyay, A., J. Electrochem. Soc. 2017, 164, A2360-A2367.

(15)Ji, B.; Zhang, F.; Song, X.; Tang, Y., A Novel Potassium-Ion-Based Dual-Ion Battery. Adv. Mater. 2017, 29, 700519.

(16)Idota, Y., Tin-Based Amorphous Oxide: A High-Capacity Lithium-Ion-Storage Material. Science 1997, 276, 1395-1397.

(17)Shimizu, M.; Usui, H.; Sakaguchi, H., Electrochemical Na-Insertion/Extraction Properties of Sno Thick-Film Electrodes Prepared by Gas-Deposition. J. Power Sources 2014, 248, 378-382.

(18)Obrovac, M. N.; Chevrier, V. L., Alloy Negative Electrodes for Li-Ion Batteries. Chem. Rev. 2014, 114, 11444-502.

(19)Li, Z.; Ding, J.; Mitlin, D., Tin and Tin Compounds for Sodium Ion Battery Anodes: Phase Transformations and Performance. Acc. Chem. Res. 2015, 48, 1657-1665.

(20) Sultana, I.; Ramireddy, T.; Rahman, M. M.; Chen, Y.; Glushenkov, A. M., Tin-Based Composite Anodes for Potassium-Ion Batteries. Chem. Comm. 2016, 52, 9279-9282.

(21)Wang, Q.; Zhao, X.; Ni, C.; Tian, H.; Li, J.; Zhang, Z.; Mao, S. X.; Wang, J.; Xu, Y., Reaction and Capacity-Fading Mechanisms of Tin Nanoparticles in Potassium-Ion Batteries. The $J$. Phys. Chem. C 2017, 121, 12652-12657.

(22) Mueller, F.; Bresser, D.; Chakravadhanula, V. S. K.; Passerini, S., Fe-Doped $\mathrm{SnO}_{2}$ Nanoparticles as New High Capacity Anode Material for Secondary Lithium-Ion Batteries. J. Power Sources 2015, 299, 398-402.

(23)Kim, C.; Noh, M.; Choi, M.; Cho, J.; Park, B., Critical Size of a Nano $\mathrm{SnO}_{2}$ Electrode for LiSecondary Battery. Chem. Mater. 2005, 17, 3297-3301.

(24)Sinha, A. K.; Manna, P. K.; Pradhan, M.; Mondal, C.; Yusuf, S. M.; Pal, T., Tin Oxide with a P-N Heterojunction Ensures Both Uv and Visible Light Photocatalytic Activity. RSC Adv. 2014, 4, 208-211. 
(25)Guo, Y. Q.; Tan, R. Q.; Li, X.; Zhao, J. H.; Luo, Z. L.; Gao, C.; Song, W. J., Shape-Controlled Growth and Single-Crystal Xrd Study of Submillimeter-Sized Single Crystals of SnO. CrystEngComm 2011, 13, 5677-5680.

(26)Geurts, J.; Rau, S.; Richter, W.; Schmitte, F. J., SnO Films and Their Oxidation to $\mathrm{SnO}_{2}$ : Raman Scattering, IR Reflectivity and X-Ray Diffraction Studies. Thin Solid Films 1984, 121, $217-225$. 
Table of Contents (TOC) Image

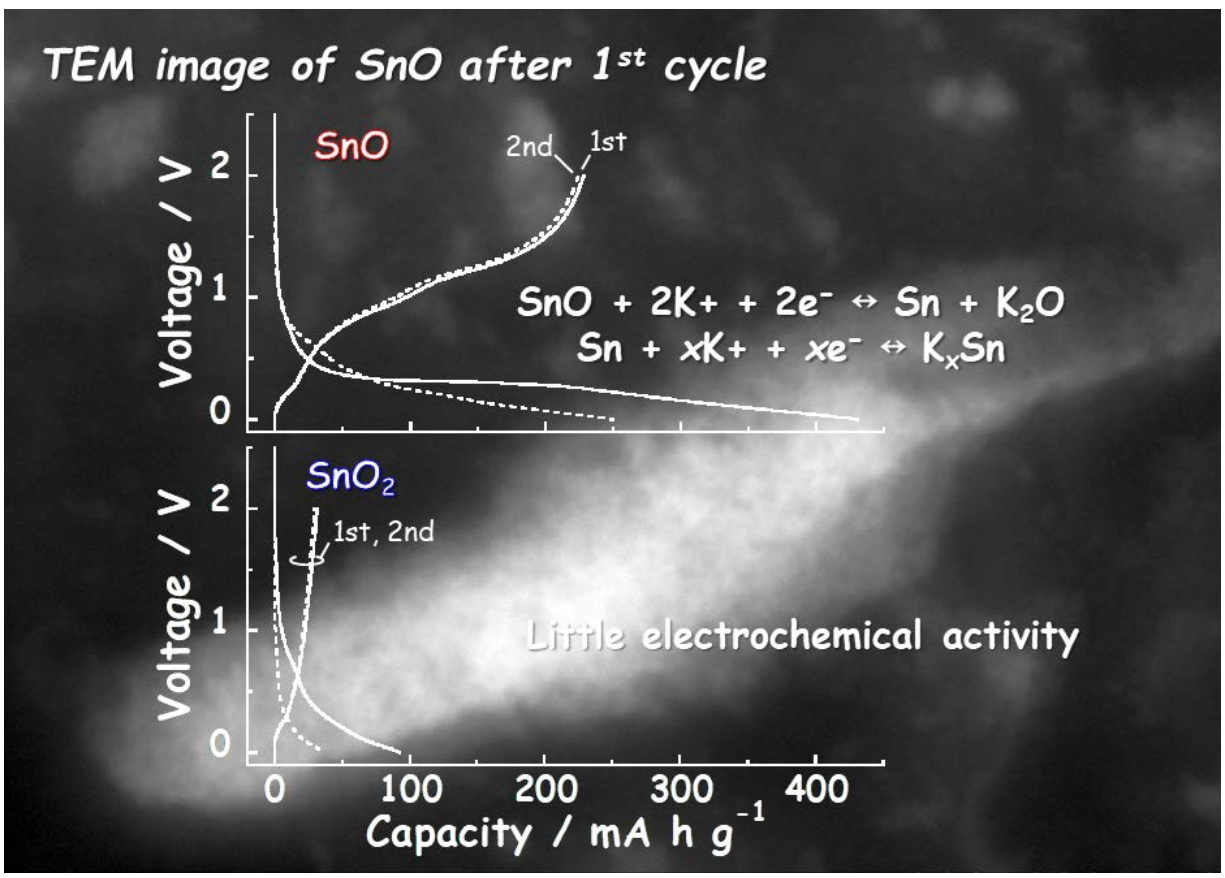




\section{Supporting Information}

\section{Tin Oxides as a Negative Electrode Material for Potassium-Ion Batteries}

${ }^{\dagger}$ Department of Materials Chemistry, Faculty of Engineering, Shinshu University

${ }^{\ddagger}$ Institute of Carbon Science and Technology, Faculty of Engineering, Shinshu University

$\S$ Technical Division, Faculty of Engineering, Shinshu University

4-17-1 Wakasato, Nagano 380-8553, Japan

Masahiro Shimizu, ${ }^{,+,, \neq}$Ryosuke Yatsuzuka, ${ }^{\ddagger}$ Taro Koya, ${ }^{\ddagger}$

Tomohiko Yamakami ${ }^{\S}$, Susumu Arai, ${ }^{*,+,}$

*Corresponding author: Dr. Masahiro Shimizu

E-mail: shimizu@shinshu-u.ac.jp

Tel: +81-26-269-5627; Fax: +81-26-269-5627 

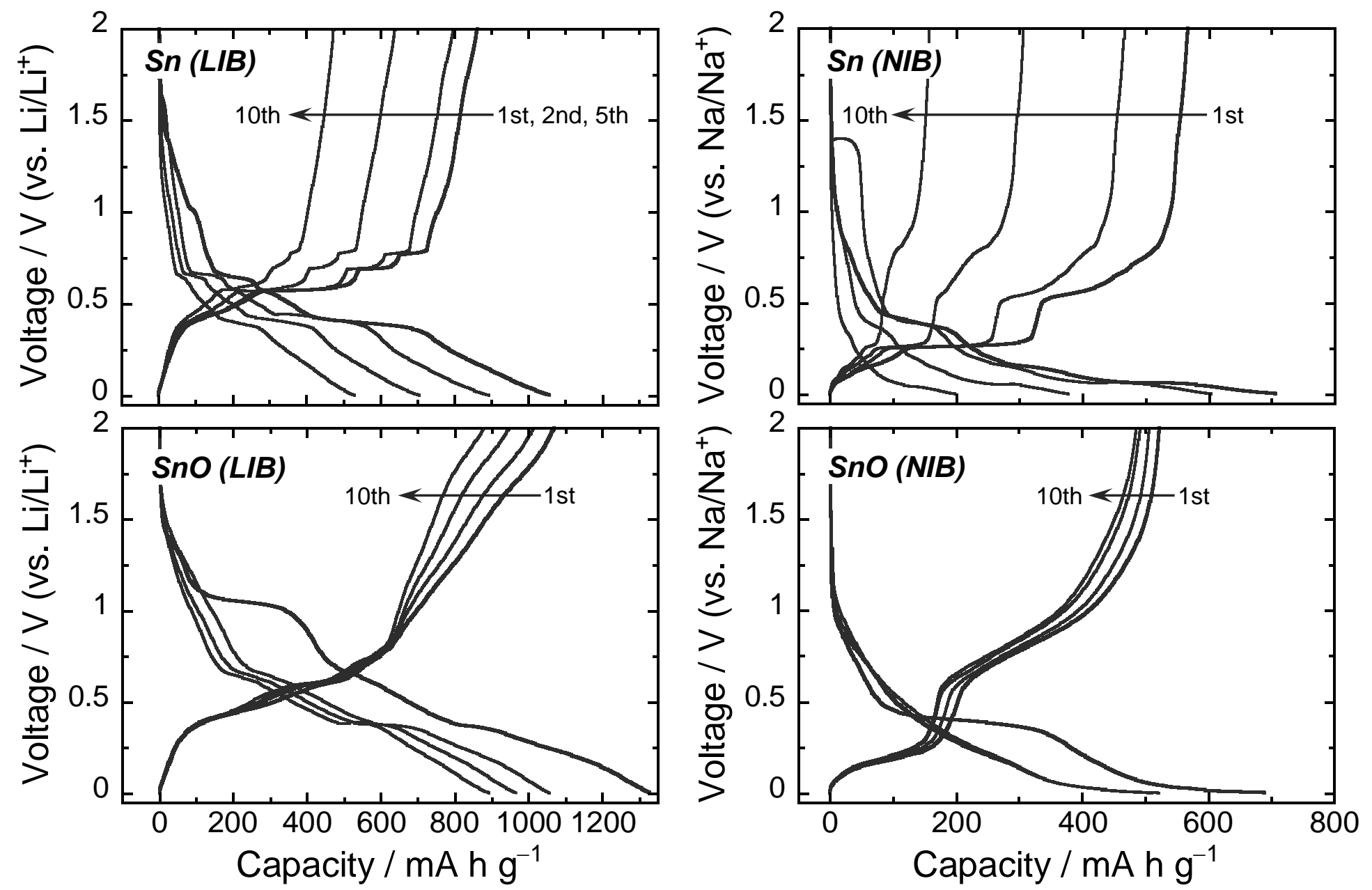

Figure S1. Charge-discharge ( $M$-insertion/extraction; $M=\mathrm{Li}, \mathrm{Na}$ ) profiles of $\mathrm{Sn}$ and $\mathrm{SnO}$ electrodes in 1.0 M MPF$/ \mathrm{EC}: \mathrm{DEC}(50: 50$ vol.\%) under a constant current density $\left(25 \mathrm{~mA} \mathrm{~g}^{-1}\right)$ in the potential range of $0.005-2.000 \mathrm{~V}$. $\mathrm{SnO}$ as negative electrodes for LIBs and NIBs showed good capacity retention compared with those of $\mathrm{Sn}$ alone electrodes. 


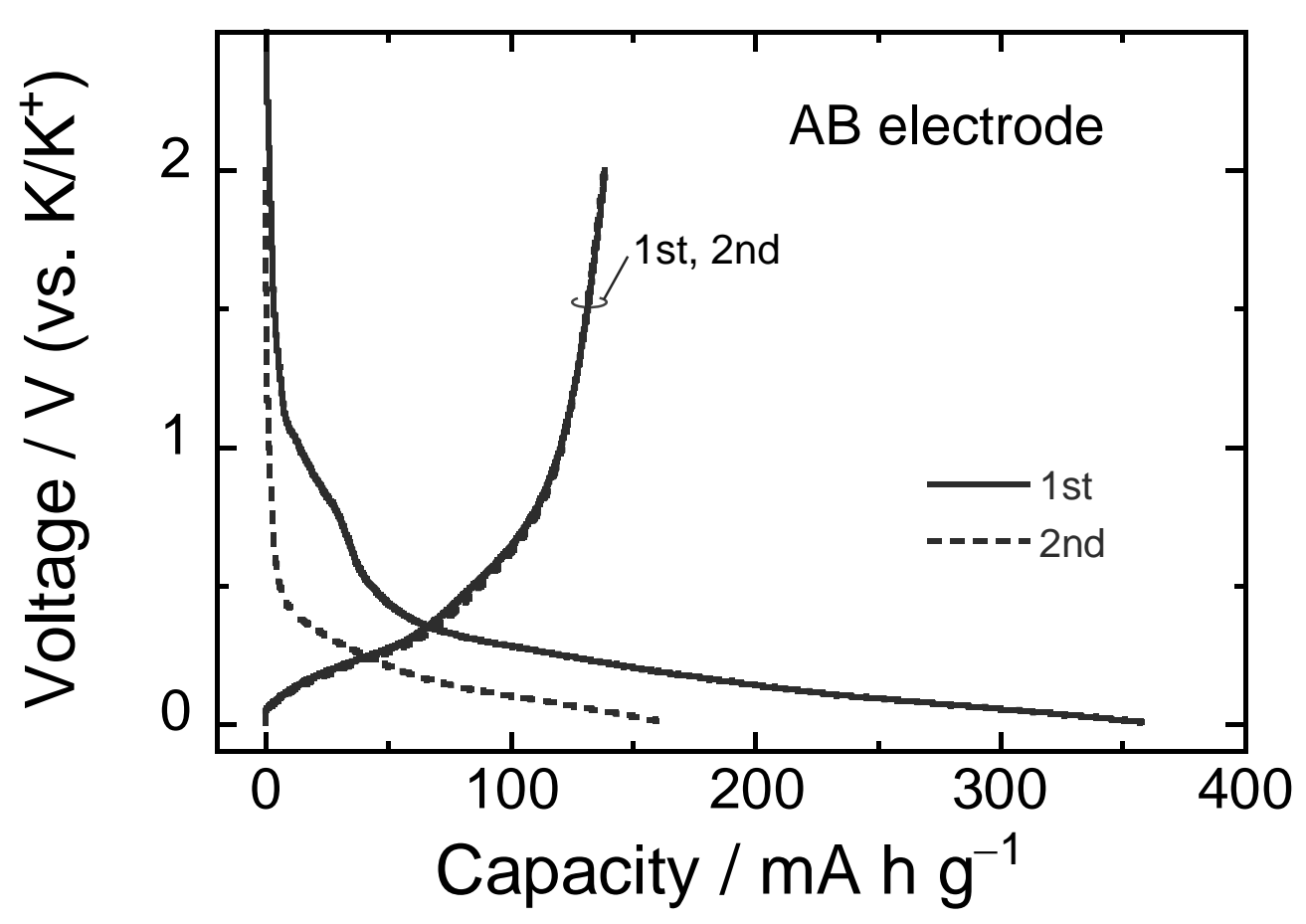

Figure S2. Charge-discharge curves of acetylene black (conductive additive) electrode in $0.5 \mathrm{M} \mathrm{KPF}_{6} / \mathrm{EC}: \mathrm{DEC}$. Current density: $25 \mathrm{~mA} \mathrm{~g}^{-1}$. Electrode composition ratio: $\mathrm{AB} / \mathrm{CMC} / \mathrm{SBR}=85 / 10 / 5 \mathrm{wt} . \%$.

$\mathrm{AB}$ electrode showed initial charge and discharge capacities of $358 \mathrm{~mA} \mathrm{~h} \mathrm{~g}^{-1}$ and $139 \mathrm{~mA} \mathrm{~h} \mathrm{~g}^{-1}$, respectively. The poor efficiency comes from the formation of surface layer involved in electrolyte decomposition. 


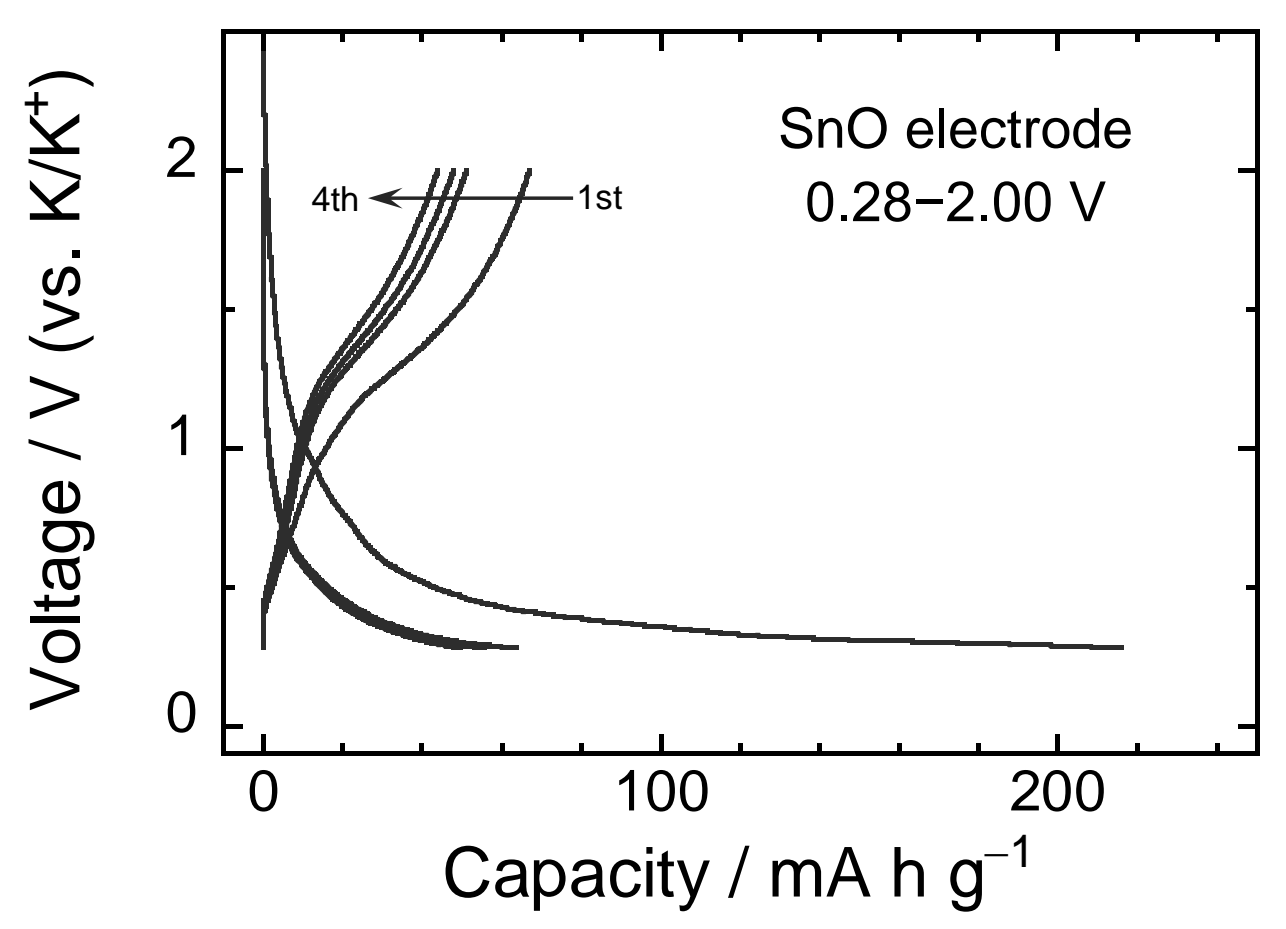

Figure S3. Charge-discharge curves of $\mathrm{SnO}$ electrode in $0.5 \mathrm{M}$ $\mathrm{KPF}_{6} / \mathrm{EC}: \mathrm{DEC}$ at the voltage range of $0.28-2.00 \mathrm{~V}$ (vs. K/K ${ }^{+}$). We conducted the test to ascertain whether a conversion reaction $\left(\mathrm{SnO}+2 \mathrm{~K}^{+}+2 \mathrm{e}^{-} \leftrightarrow \mathrm{Sn}+\right.$ $\mathrm{K}_{2} \mathrm{O}$ ) occurred reversibly or not. In the voltage range without $\mathrm{K}-\mathrm{Sn}$ alloying reactions, an initial reversible capacity of $67 \mathrm{~mA} \mathrm{~h} \mathrm{~g}^{-1}$ was obtained and the capacity gradually decreased. 

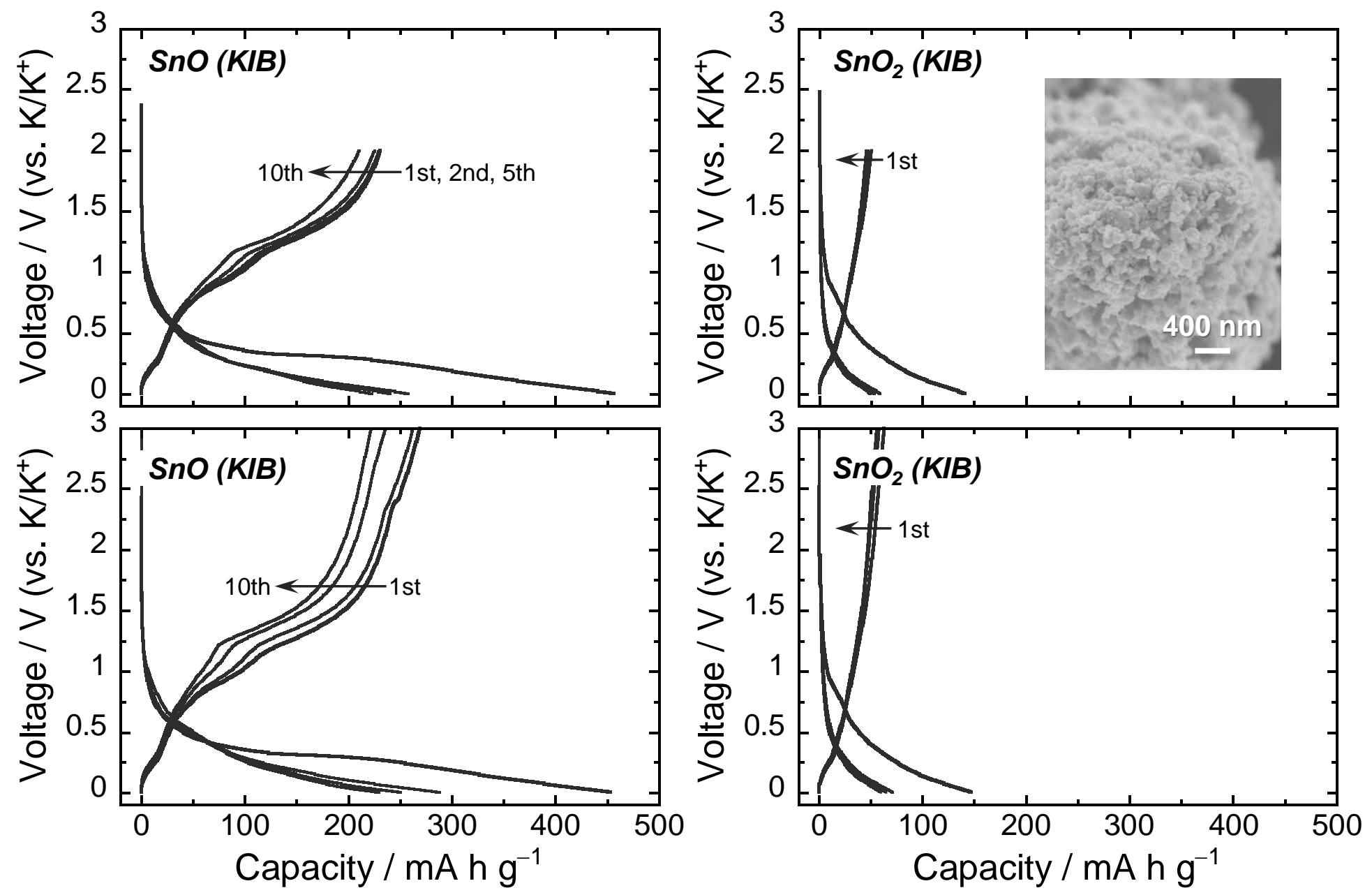

Figure S4. Charge-discharge profiles (1st, 2nd, 5th, 10th) of $\mathrm{SnO}$ and $\mathrm{SnO}_{2}$ electrodes in $0.5 \mathrm{M} \mathrm{KPF}_{6} / \mathrm{EC}: \mathrm{DEC}(50: 50 \mathrm{vol} . \%)$ under a constant current density in the voltage range of $0.005-2.000 \mathrm{~V}$. $\mathrm{SnO}$ and $\mathrm{SnO}_{2}$ powders were pulverized to submicron size by mechanical milling $(380 \mathrm{rpm}, 1 \mathrm{~h})$. The upper cut-off voltage was changed from $2.0 \mathrm{~V}$ to $3.0 \mathrm{~V}\left(\mathrm{vs} . \mathrm{K} / \mathrm{K}^{+}\right.$). 


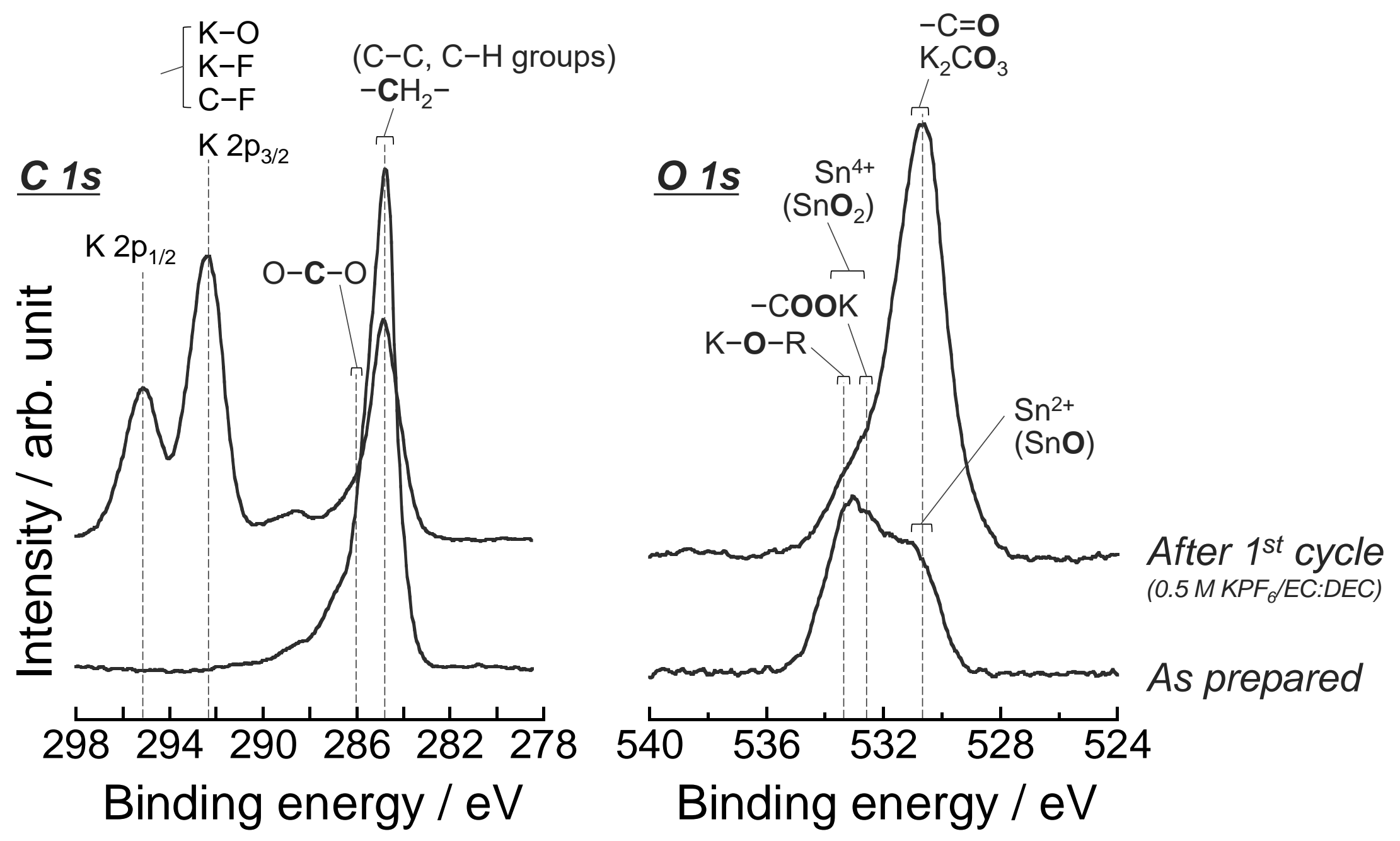

Figure S5. XPS spectra of $\mathrm{C} 1 \mathrm{~s}$ and region for $\mathrm{SnO}$ electrodes before and after the first depotassiation cycle $\left(2.0 \mathrm{~V}\right.$ vs. $\left.\mathrm{K} / \mathrm{K}^{+}\right)$. XPS spectra were calibrated using the binding energy of hydrocarbon $(\mathrm{C}-\mathrm{C}, \mathrm{C}-\mathrm{H}$ groups $)$ at $284.6 \mathrm{eV}$. An incident $\mathrm{X}$-ray source is monochromatic radiation (Al-Ka, $1486.6 \mathrm{eV}$ ) and was operated at $25 \mathrm{~W}$. 


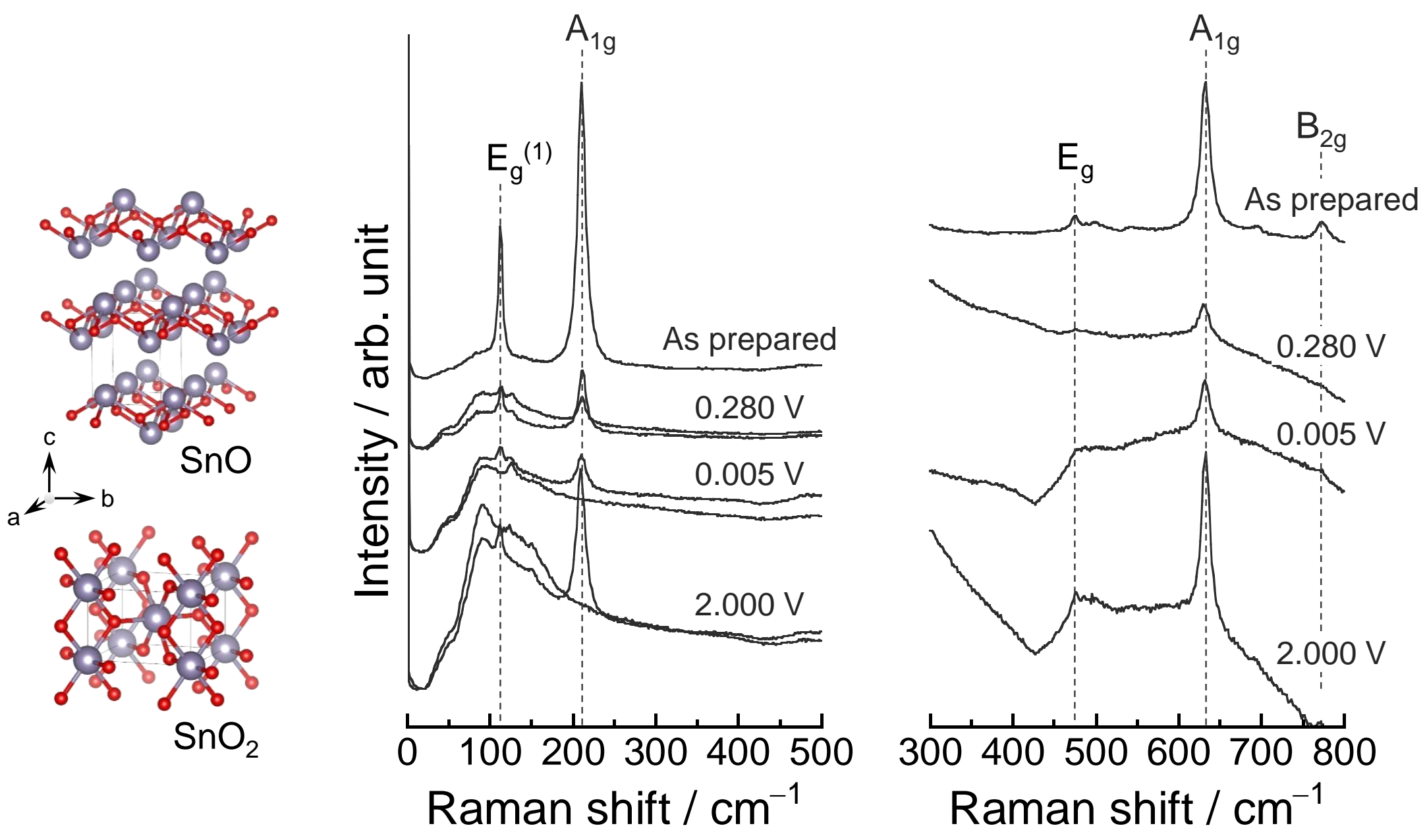

Figure S6. Ex-situ Raman spectra of (a) $\mathrm{SnO}$ and (b) $\mathrm{SnO}_{2}$ electrodes during the first potassium-insertion cycle. In order to avoid the effect of water in air, the sample was transferred to a quartz cell and tightly sealed in an argon atmosphere. As for $\mathrm{SnO}$ electrode, two spectra at the different regions in each voltage were shown. 
Raman spectra of $\mathrm{SnO}$ and $\mathrm{SnO}_{2}$ electrodes during the first cycle, which assists understanding of reaction mechanism with potassium. In the as-prepared $\mathrm{SnO}$ electrode, several Raman bands (between 50 to $150 \mathrm{~cm}^{-1}$ ) were confirmed. The Raman bands located at $113\left(\mathrm{E}_{1 \mathrm{~g}}\right)$ and $210 \mathrm{~cm}^{-1}\left(\mathrm{~A}_{1 \mathrm{~g}}\right)$ suggest the formation of wellcrystallized $\mathrm{SnO}$. In the fully charged state at $0.005 \mathrm{~V}\left(\mathrm{vs} . \mathrm{K} / \mathrm{K}^{+}\right)$, both of these bands disappeared in some regions, which indicated that $\mathrm{Sn}-\mathrm{O}-\mathrm{Sn}$ bond broke and $\mathrm{K}-\mathrm{Sn}$ alloys were formed. At another region, $E_{1 \mathrm{~g}}$ and $\mathrm{A}_{1 \mathrm{~g}}$ bands were recognized, and the phenomenon indicates that the complete transformation of $\mathrm{SnO}$ to $\mathrm{Sn}$ (reduction reaction $/ \mathrm{SnO}+2 \mathrm{~K}^{+}+2 \mathrm{e}^{-} \rightarrow \mathrm{Sn}+\mathrm{K}_{2} \mathrm{O}$ ) did not proceed. In $\mathrm{SnO}_{2}$ electrode, the bands of $\mathrm{E}_{1 \mathrm{~g}}, \mathrm{~A}_{1 \mathrm{~g}}$ and $\mathrm{B}_{2 \mathrm{~g}}$ derived from $\mathrm{SnO}_{2}$ crystal constantly appeared irrespective of reaction voltages. It is considered that $\mathrm{SnO}_{2}$ has a little electrochemical reactivity to potassium. 


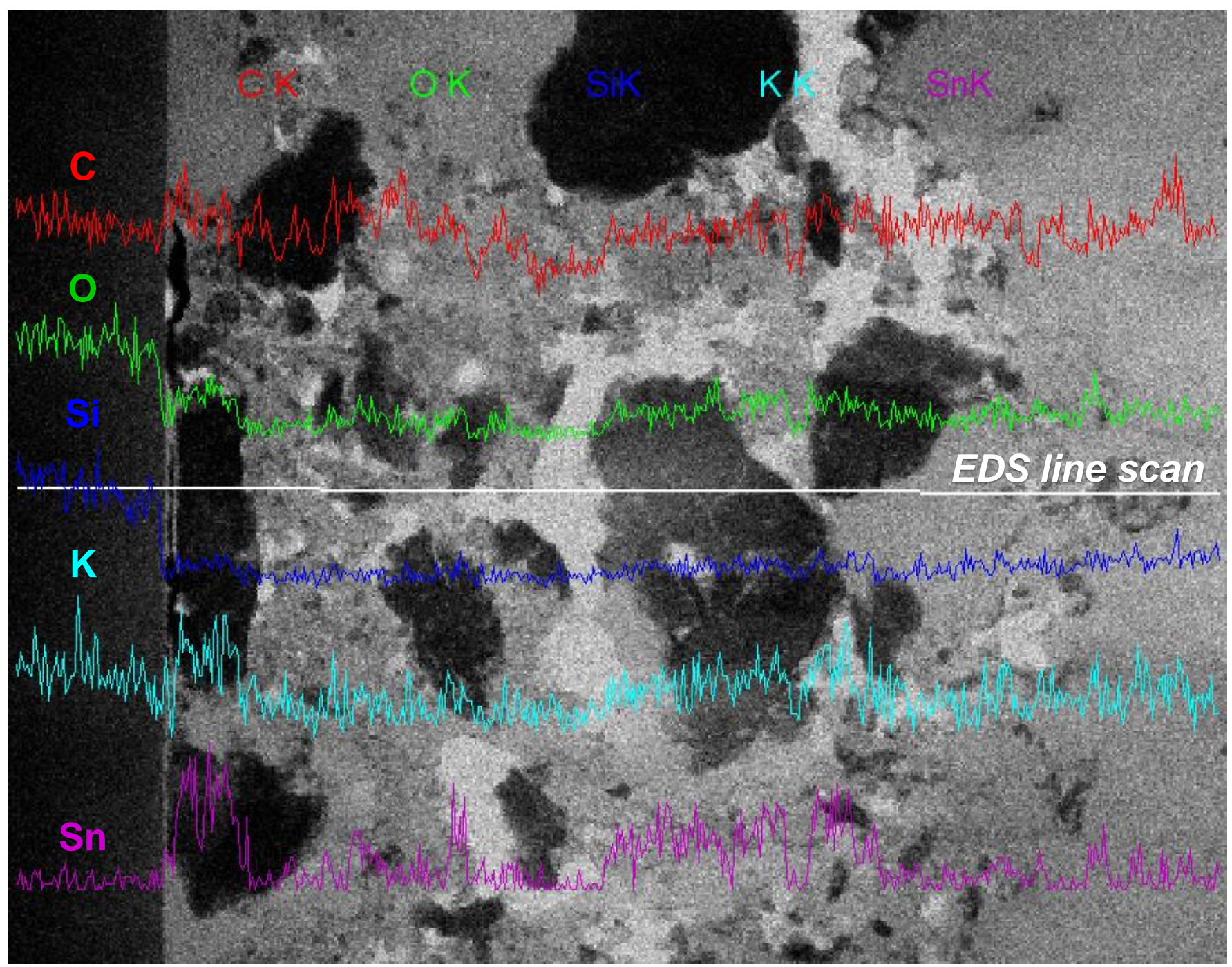

Figure S7. STEM image and a result of EDS line scan of sliced SnO electrode after the first potassiaiton cycle in 0.5 $\mathrm{M} \mathrm{KPF}_{6} / \mathrm{EC}: \mathrm{DEC}$ (50:50 vol.\%). Dark regions indicates the existence of Sn element. 


\section{SnO electrode after $1^{\text {st }}$ cycle}

STEM image

\section{SnO electrode after $1^{\text {st }}$ cycle}

HAADFimage
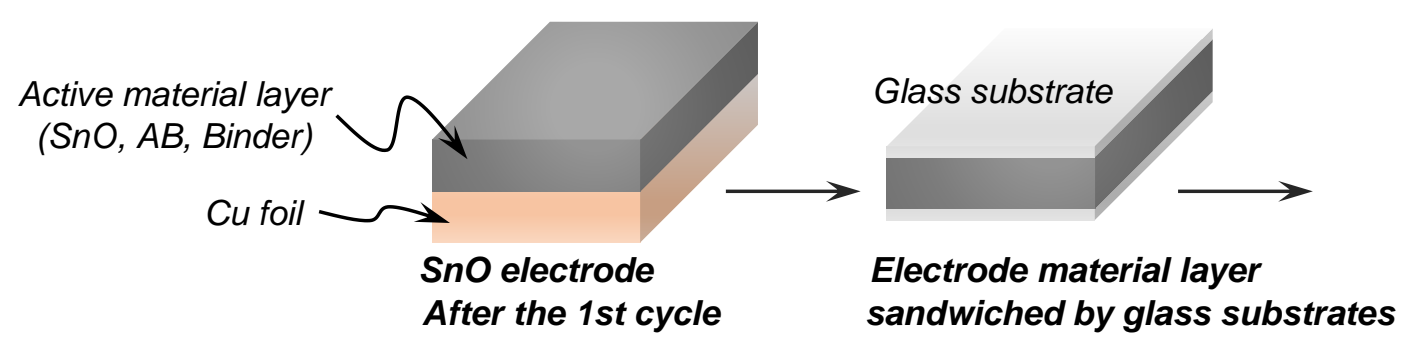

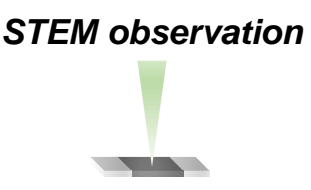

Sliced sample for STEM observation

Figure S8. STEM and HADDF images of $\mathrm{SnO}$ electrode after the first potassiaiton cycle in $0.5 \mathrm{M} \mathrm{KPF}_{6} / \mathrm{EC}: \mathrm{DEC}$. The electrode (active material layer) was peeled off from $\mathrm{Cu}$ current collector by using epoxy resin, and then it was immobilized on a smooth glass substrate. The sample was sliced by means of ion milling apparatus. 


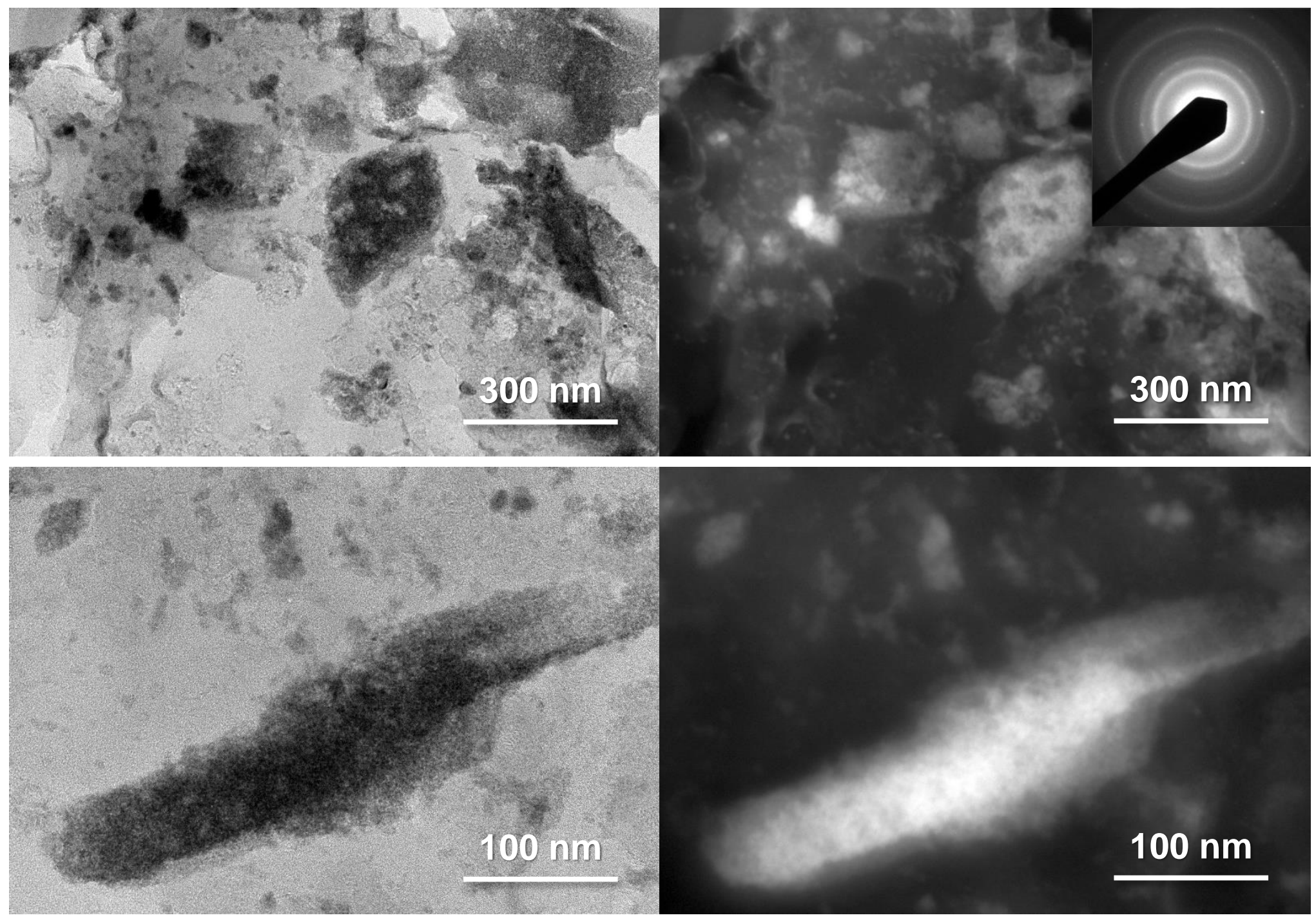

Figure S9. TEM and contrast images of $\mathrm{SnO}$ electrode after the first potassiaiton cycle in $0.5 \mathrm{M} \mathrm{KPF}_{6} / \mathrm{EC}$ :DEC. Since the single particle consists of light and dark region in the contrast images, $\mathrm{SnO}$ particles appear to undergo phase separation to form metallic $\mathrm{Sn}$ and $\mathrm{K}_{2} \mathrm{O}$ matrix. 


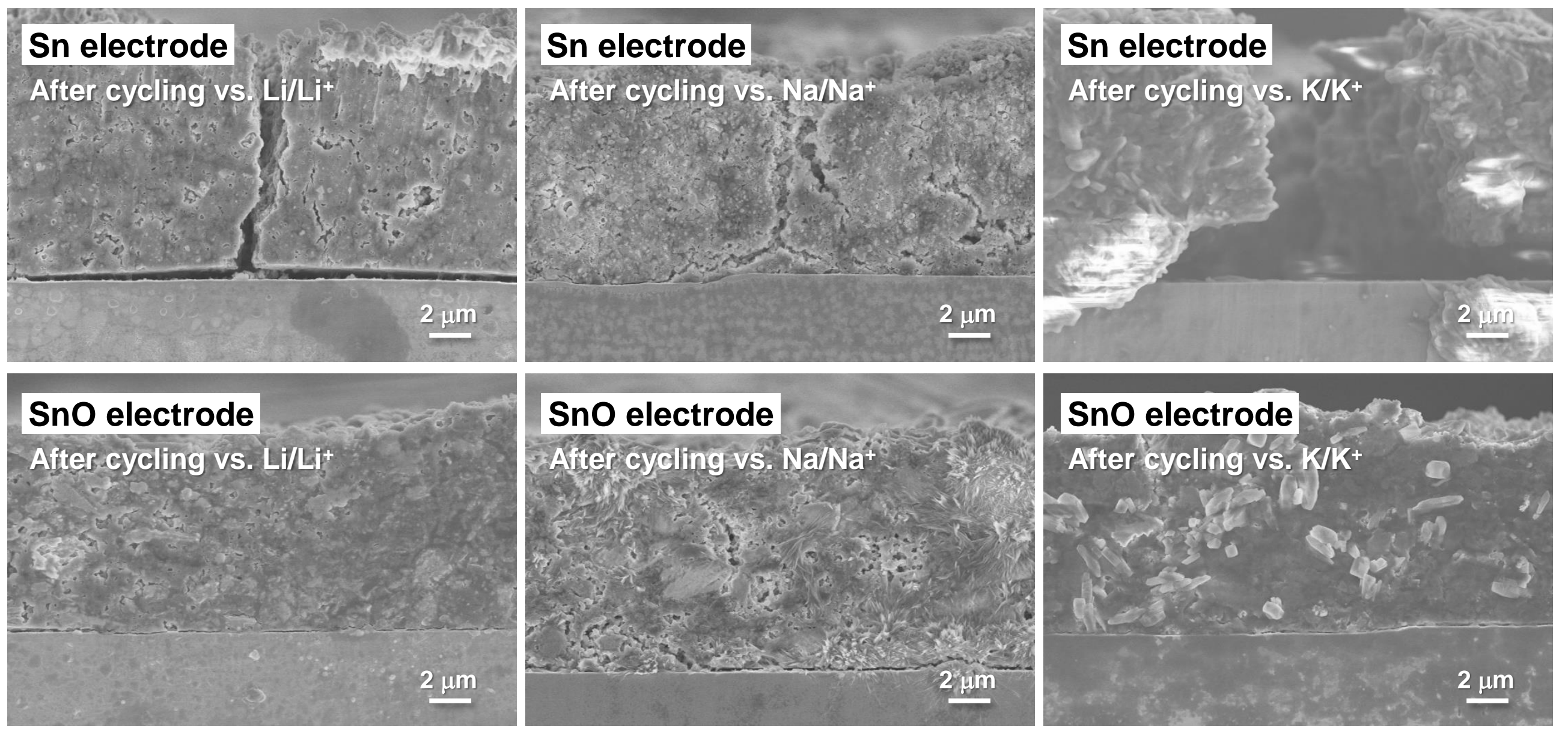

Figure S10. Cross-sectional FE-SEM images of Sn and SnO electrodes after the 10th cycle in 1.0 $\mathrm{M} \mathrm{LiPF}_{6} / \mathrm{EC}: \mathrm{DEC}, 1.0 \mathrm{M} \mathrm{NaPF}_{6} / \mathrm{EC}: \mathrm{DEC}$, and $0.5 \mathrm{M}$ $\mathrm{KPF}_{6} / \mathrm{EC}: \mathrm{DEC}$ (50:50 vol.\%). Large cracks and detachment of active material layer from current collectors were clearly observed in the $\mathrm{Sn}$ electrodes regardless the difference in alkali metal ion occluded, whereas no electrode disintegration was confirmed in the $\mathrm{SnO}$ electrodes. 


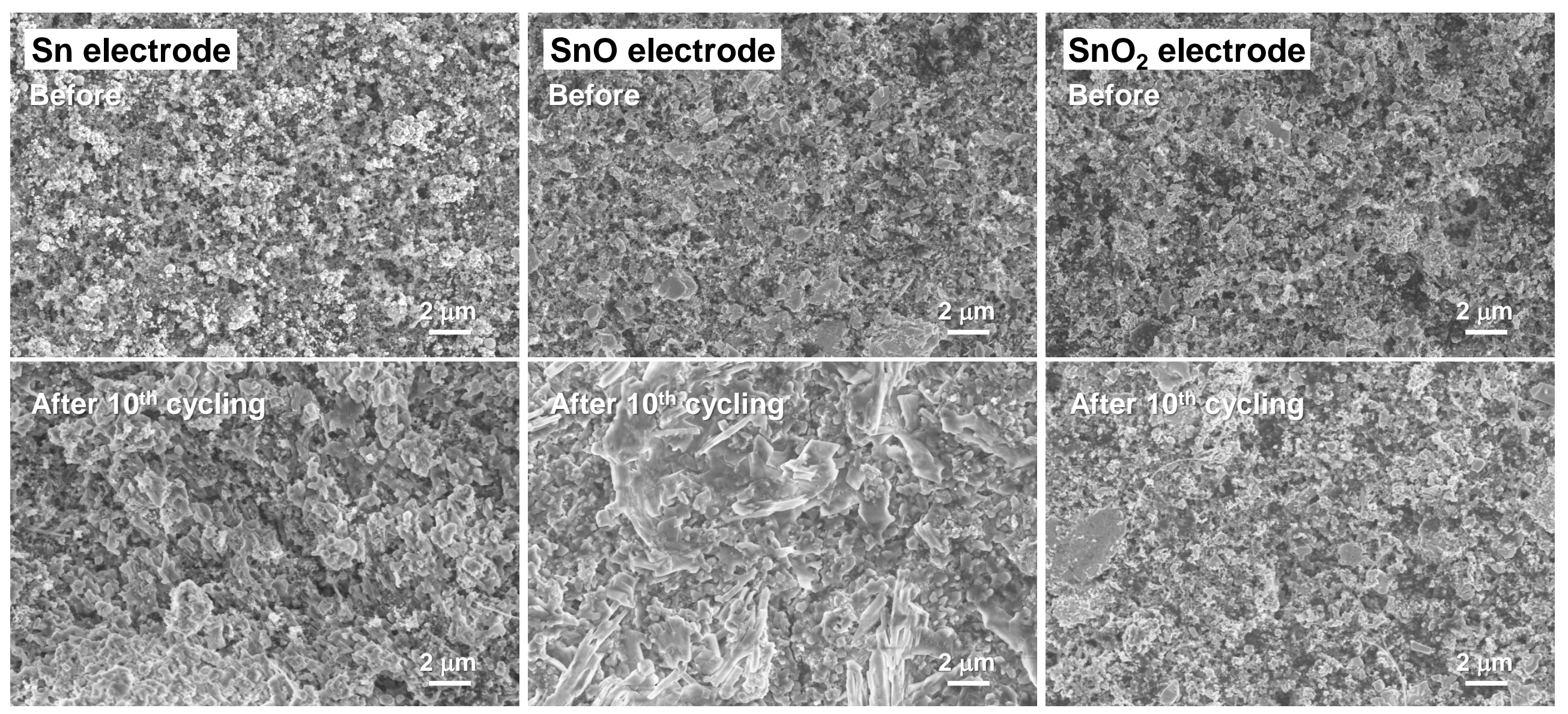

Figure S11. Surface FE-SEM images of $\mathrm{Sn}, \mathrm{SnO}$, and $\mathrm{SnO}_{2}$ electrodes after the 10th cycle. Disintegration of Sn electrode related to rapid capacity fading was observed. It appears that $\mathrm{Sn}$ generated from phase separation of $\mathrm{SnO}$ aggregated. In contrast, there is little change in $\mathrm{SnO}_{2}$ electrode. 

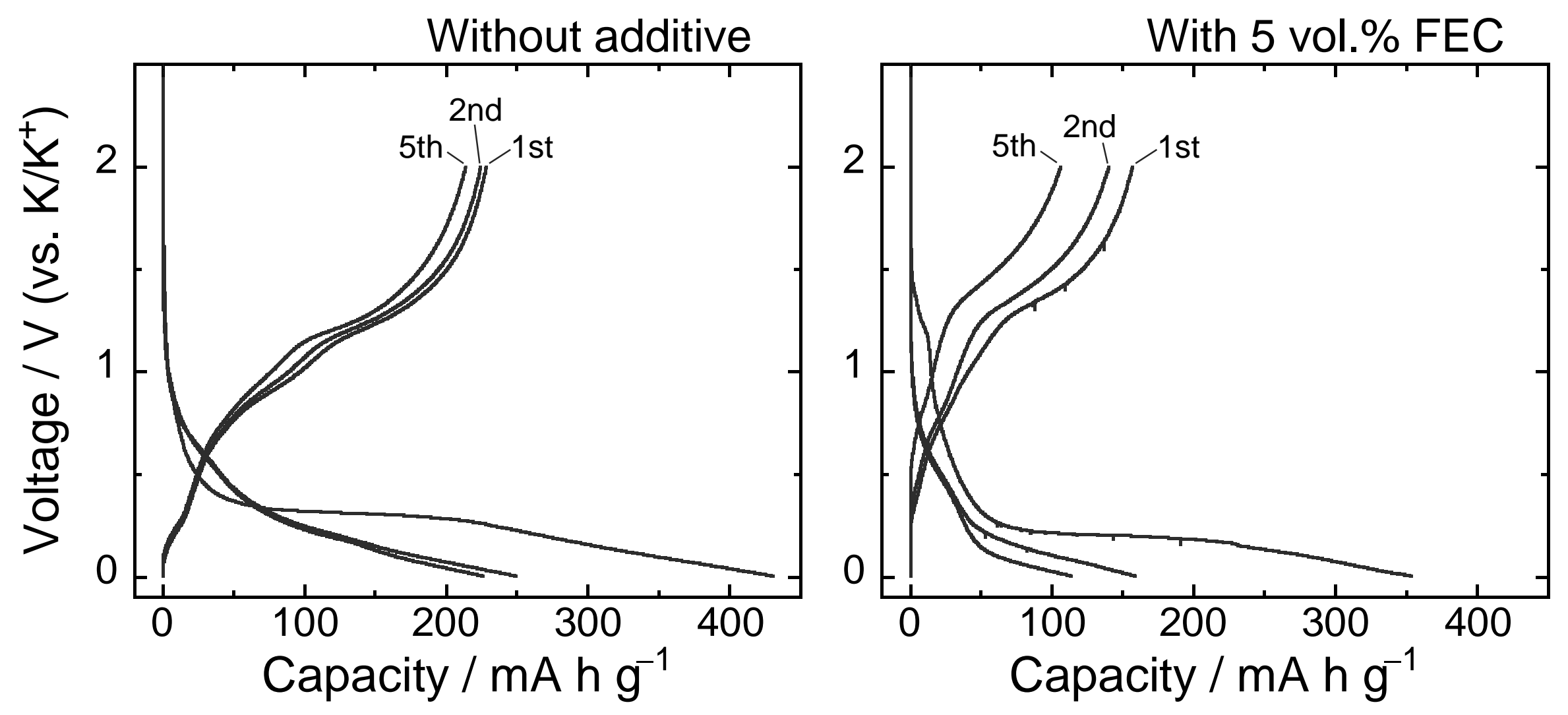

Figure S12. Charge-discharge (K-insertion/extraction) profiles $\mathrm{SnO}$ electrodes in $0.5 \mathrm{M} \mathrm{KPF}_{6} / \mathrm{EC}: \mathrm{DEC}$ (50:50 by volume) with and without 5 vol.\% fluoroethylene carbonate (FEC). Current density: $25 \mathrm{~mA} \mathrm{~g}^{-1}$. Effect of FEC additive on electrochemical performance was evaluated. In $\mathrm{SnO}$ as a negative electrode material for $\mathrm{Li}$-ion and $\mathrm{Na}$-ion batteries, cycle stability is improved by addition of FEC. In contrast, the performance under operation of K-ion battery electrode became poor than that in without additive. 